ISSN 2693-2504

\title{
Glutathione As Biomarker for Neurodegenerative Diseases
}

Journal of Bioscience \& Biomedical Engineering

Mini Review

Shimon Shatzmiller*, Inbal Lapidot

Department of Biological Chemistry, Ariel University of Samara, 40700 Ariel, Israel

\author{
"Correspondence author \\ Shimon Shatzmiller \\ Department of Biological Chemistry \\ Ariel University of Samara \\ 40700 Ariel \\ Israel
}

Submitted : 24 Aug 2020 ; Published : 18 Sept 2020

\begin{abstract}
Brain imaging is one of the main obstacles of modern disease diagnostics since it must allow accurate and quantitative measurements on a living organ that is placed in adults (in neonatal humans' skull penetration is somewhat easier) inside a bone cage. Inside is the brain, the main function controller of our body that must be done in a non-invasive way on the living operation brain. Many spectroscopic methods are trying to overcome the difficult access to the brain: Photoacoustic microscopy, Confocal microscopy, Two-photon microscopy, Optical coherence tomography, Scanning Laser Acoustic Microscopy, Acoustic microscopy, Ultrasonography, positron tomography, fluorescence methods, photo caustic microscopy and multi (two) photon imaging spectroscopy. The situation is complex since the brain is wrapped in the blood brain barrier allowing only selected molecules to pass from the blood stream to and out of the brain. In this chapter, we will survey the current situation of brain diagnostics with the aid of the spectroscopic methods. Brain research is integrated in aging research as a major area of interest. Aging is in most cased coupled with the loss of brain function and dementia. The neurodegenerative diseases, although identified by Dr. Alzheimer and his collaborators more than a century ago, continue as the leading causes of mortality among the elderly. Brain research in trying to give hope to those people but unfortunately our understanding in this area is limited. Oxidative stress contributes to neurodegenerative diseases pathophysiology and progression. The target was to describe central and peripheral metabolites of redox metabolism and to describe correlations between glutathione status, age, and disease severity.
\end{abstract}

\section{Opening Words}

The brain is the organ known to have its own guarding system, a huge blood vessels net that allows the entry of essential nutrients while blocking other substances. Unfortunately, this barrier is so effective in protecting against the passage of foreign substances that it may prevent life-saving drugs from being able to repair the damaged brain $[1,2]$. A partial list of more than 20 amyloid-related diseases includes Alzheimer's Disease, Parkinson's Disease, Huntington's Disease, prion diseases, familial amyloidosis, type II diabetes, CreutzfeldtJakob disease, Lewy Body Dementia and more than 20 more uncurbable and therefore fatal diseases. New studies are guiding researchers toward a breakthrough in the cure of non-infectious neurodegenerative diseases are associated with the accumulation of fibrillar proteins. These diseases exhibit features that are reminiscent of those of prionopathies, including phenotypic diversity and the propagation of pathology of Proteopathy ( refers to a class of diseases in which certain proteins become structurally abnormal, and thereby disrupt the function of cells, tissues and organs of the body.). Retinopathies are the abnormal accumulation and toxicity of proteins in certain disease states. [3] Also, selective hyper proteolytic diseases have been referred to this category, e.g. critical illness myopathies or tumor cachexia [2]. The retinopathies comprise at least 30 diseases that affect a variety of organs and tissues, including Alzheimer's Disease (AD), Parkinson's Disease, type 2 diabetes, amyloidosis, and a wide range of other disorders $[4,5]$.

In some retinopaths, an abnormal assembly can be designed on an exogenous protein, usually in the folded form of the same protein. In this way the disease state in a susceptible host can be induced by inserting a diseased tissue extract from an infected donor. The best known form of such an infectious (or transmitted) protopathy is a fertility disease, which can be transmitted by exposure of a host organism to a purified fertility protein in a disease-causing structure [6,7]. There 
is now evidence that other protopaths can be injected by a similar mechanism, including amyloidosis AA, apolipoprotein AII amyloidosis, and amp amyloidosis [8,9]. In all of these cases, an aberrant form of the protein itself appears to be the pathogenic agent. Already one hundred years ago, Jacob Heinrich Lewy described intracellular eosinophilic inclusions in the brains of patients with "paralysis agitos ", commonly known as Parkinson's Disease [10].

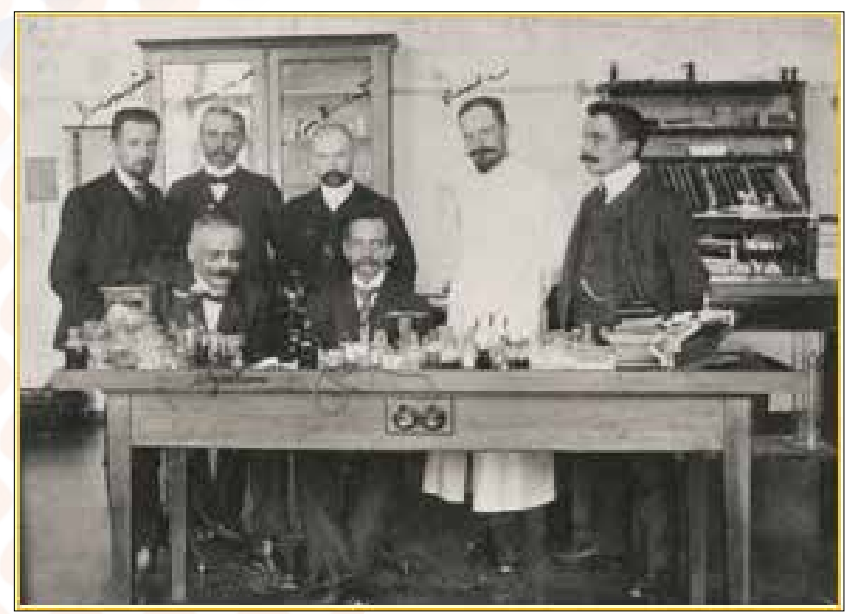

A group of psychiatrists at the Psychiatric Clinic at the University of Munich: A. Alzheimer and Solomon

Fuller sit in the front row; Standing in the back row, from left to right: Bronciini, Bronciini, von Norbert, Ranky, and unidentified.

Mighty progress has been made over the past decades in analyzing the content and formation of Levy bodies and their relationship to degenerative diseases. Multitudes of researchers have been engaged in the last hundred years since the identification of the phenomenon. However, only little has been achieved in the diagnosis of the initial stages of the diseases. Here we try to survey the chemistry aspect of the diagnostic efforts.

The health authorities in the USA gathered some information on the effort in the chemistry of neurodegenerative diseases. A sample could be found on the Internet [11].

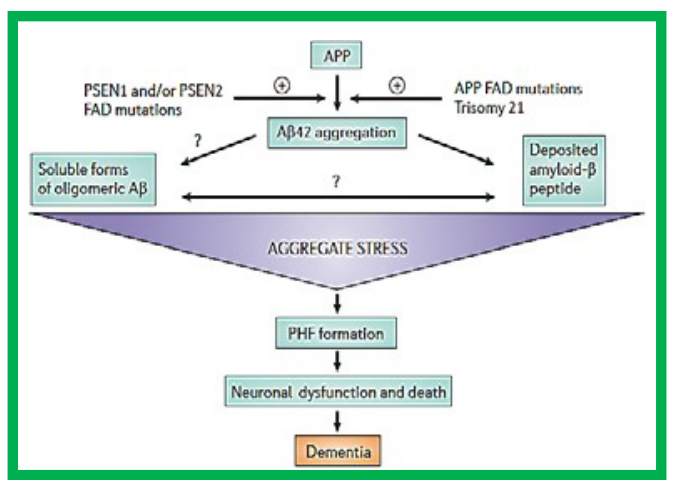

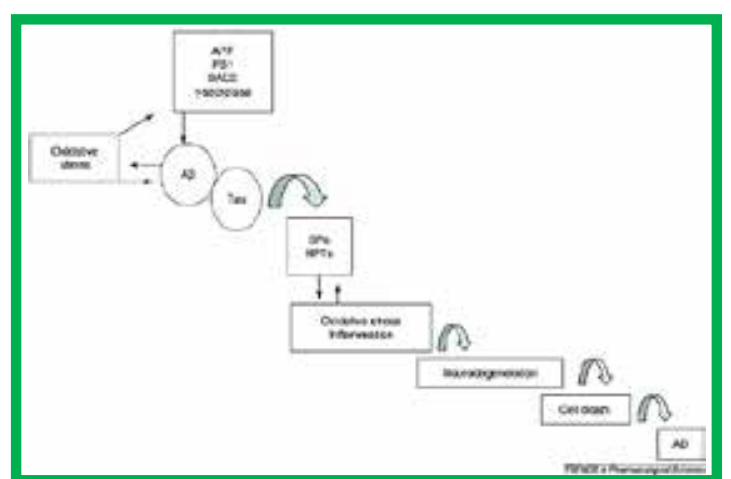

Amyloid Beta Hypothesis Oxidative stress Hypothesis, Glutathione [12-14]

It has been more than 10 years since it was first proposed that the neurodegeneration in Alzheimer's disesse (AD) may be caused by deposition of amyloid B-peptide (AB) in plaques in brain tissue. According to the amyloid hypothesis, accumulation of $A B$ in the brain is the primary influence driving $A D$ pathogenesis. The rest of the disease process, including formation of neurofibrillary tangles containing tau protein, is proposed to result from an imbalance between $A \beta$ production and $A \beta$ clearance)

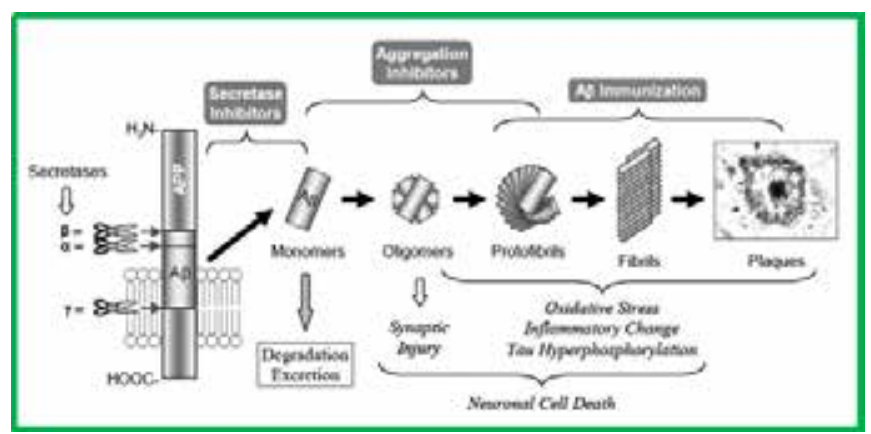

Schematic illustration of the A $\beta$-amyloid cascade from APP cleavage by secretases to generate $A \beta$ monomers, to plaque formation, via oligomers, protofibrils, and fibrils. Causative factors for neuronal injury are indicated in italic letters under the A $\beta$ pathway. Anti-amyloid agents are also shown in solid white letters above the therapeutic targets in the $A \beta$ pathway [1].

Glutathione $(\mathrm{GSH})$ is the major cellular thiol present in mammalian cells and is critical for maintenance of redox homeostasis [15]. However, current assay systems for glutathione lack application to intact animal tissues. Although reports exist on the quantitative imaging of glutathione in hippocampal neurons and glia in culture using bimane fluorescence, there is an urgent need to map the levels of glutathione in intact brain with cellular resolution (acute tissue slices and live animals) [16]. Glutathione is a major antioxidant system in the mammalian central nervous system (CNS). Abnormalities of GSH metabolism have been associated with many disorders of the CNS, including Parkinson's, Alzheimer's, and Huntingdon's diseases and ischemic/ reperfusion injury. Investigation of GSH levels in the CNS generally relies on biochemical assays from cultures enriched for different cell types.

There is Oxidative Damage Is the Earliest Event in Alzheimer Disease [17]. Glutathione S- transfer, commonly abbreviated (GST), refers to a group of enzymes that employ glutathione 
in many reactions that contribute to the conversion of many compounds such as therapeutic drugs, carcinogens, and products involved in oxidative stress. The evaluation of the enzyme Glutathione Transferases (GST), a method that may become instrumental in the choosing glutathione Transferases level as a biomarker for Alzheimer's Disease [18,19]. Scientist developed a spectrophotometric assay for the glutathione conjugation and determined specific activities with a range of human GSTs as well as some rat GSTs for comparison. The ubiquitous GST P1-1 showed the highest activities with the 6-halogenopurines, which bodes well for the application of pro-probes for human investigations.

The acceptance of the "oxidative stress" as a major process in the early evolution of neurodegenerative pathology has become a major trend in this field of research.

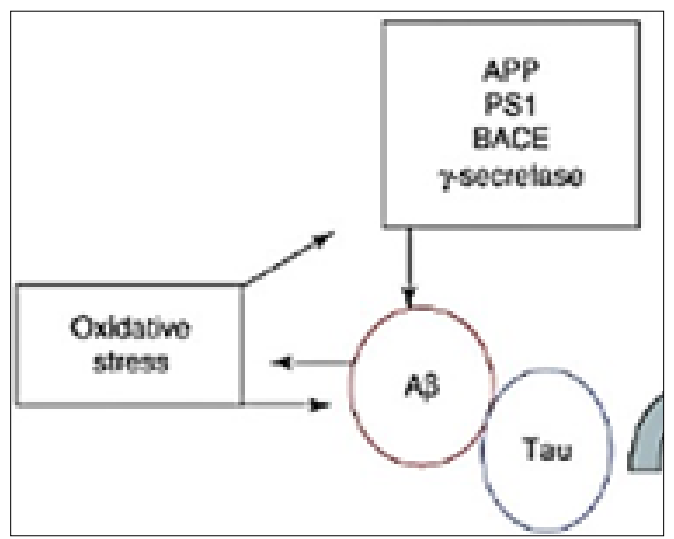

Oxidative stress early stages

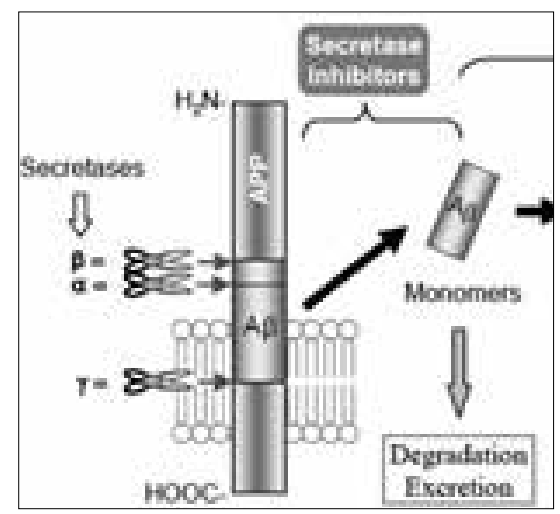

Amyloid hypothesis early stages

Digestion of beta-amyloid precursor protein is supposed to produce fractures that do not harm or harm fractures. There is an evolving consensus seeing amyloid cerebrospinal fluid $(A ß)$ as a key biological marker for the Alzheimer's disease stage of mild cognitive impairment. $A \beta$ is directly involved in the pathogenesis of $\mathrm{AD}$ or in close correlation with other primary pathogenic factors. It is produced from amyloid precursor protein (APP) by proteolytic processing dependent on the enzyme 1-closed AP-site and the $\gamma$-secretase complex, and is degraded by a wide variety of proteases. This review summarizes targeted proteolytic studies of $A \beta$ in biological fluids and identifies clinical useful markers of $A \beta$ homeostasis in $\mathrm{AD}$ disruption.
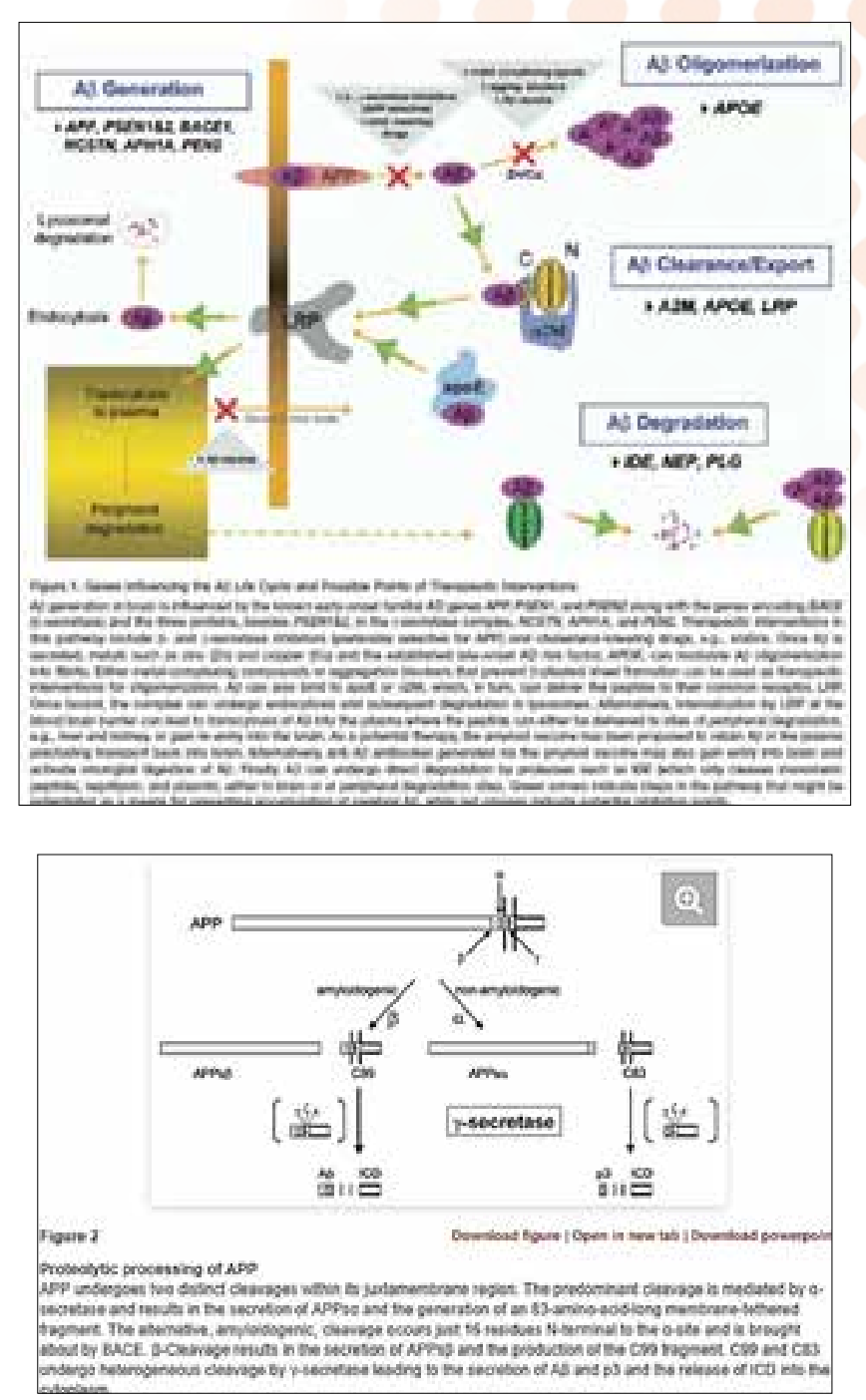

Alternative splitting b synuclein enzymes, digestion of betaamyloid precursor protein [20]. Is it a secondary effect or byproduct that arises from but does not causally influence a process, in particular.
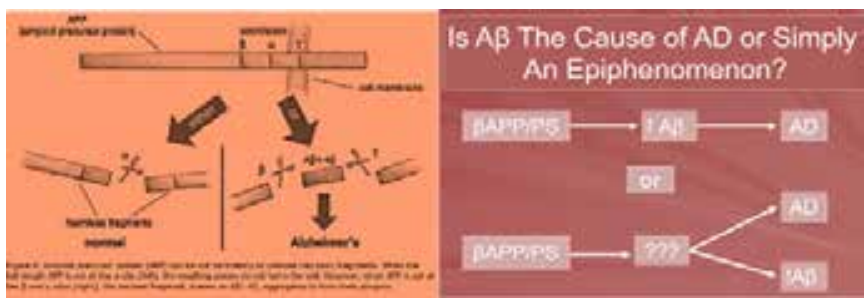

Such defects are considered to the postulated initiation of the cascadeleading to Metabolic abnormities In Alzheimer's Disease to confirm the characteristics of metabolic abnormalities in Alzheimer's Disease, regional metabolic activity summarized in tennis of quantitative cerebral glucose metabolic rate.

\section{Introduction}

Glutathione (GSH) is required for many critical cell processes, buy plays a particularly key role in the care and regulation of the thiol-redox status of the cell. GSH is the most important endogenous antioxidant and plays an important role in the 
detoxification of xenobiotics and their metabolites, as well as in the maintenance of the intracellular redox balance.

With current estimates of 36 million people affected worldwide. Alzheimer's Disease (AD) - a disorder characterized by impossible progressive impairment of memory and other cognitive functions - is the most prevalent form of dementia. Therefore, identifying biological markers that can serve as a reliable surrogate for the onset of the disease disorder and its progression is of paramount importance for information on intervention. Oxidative stress, which is a common denominator of a number of pathophysiological events associated with $\mathrm{AD}$, appears to be a major factor in the pathogenesis and progression of AD. Alzheimer's Disease (AD) represents one of the great and unresolved medical needs facing society during this thousand years. Despite considerable work over the last quarter. There are no drugs that attack the pathophysiology underlying the Disease. One of the cardinal characteristics of counting Disease is the placement of platelets composed of peptides (3-amyloid, A, s) in the brain. Especially in areas related to cognition and memory overproduction of $\mathrm{A}$ that appears to be directly neurotoxic. Can be detected in the earliest stages of $\mathrm{AD}$ and. in fact.

Before cognitive function can be discerned a father is extracted from a protein from its flesh. Amyloid precursor protein (APP), by proteolytic processing at its $\mathrm{N}$ - and $\mathrm{C}$-terminals by enzymes $\alpha, \beta$ - and $\gamma$-secretase enzymes [21,22].

Two main hypotheses are today directing neurodegenerative diseases research. The Amyloid hypothesis and the oxidative stress mechanism. Although the accumulation of data supports the Amyloid beta aggregation hypothesis, in conclusion, the oxidative stress hypothesis (inflammation) of AD is very much alive and viable, but a great deal of work needs to be done to design future studies and appropriate clinical trials that will conclusively establish the role of oxidative stress in $\mathrm{AD}$ pathogenesis.

One high hurdle is the lack of a quantitative instrumental method to diagnose and follow the Disease from initial stages. The development of new drugs depends a lot of such a helpful device.

Alzheimer's Disease is one of the many neurodegenerative disorders that are tormenting many, older people. It is in the unflavored situation where many theories on what initiates the cascade of events and when exactly it started to affect the life of the ill people [23].

Today, only a post mortem analysis of the patient brain can diagnose $100 \%$ the Alzheimer's Disease.
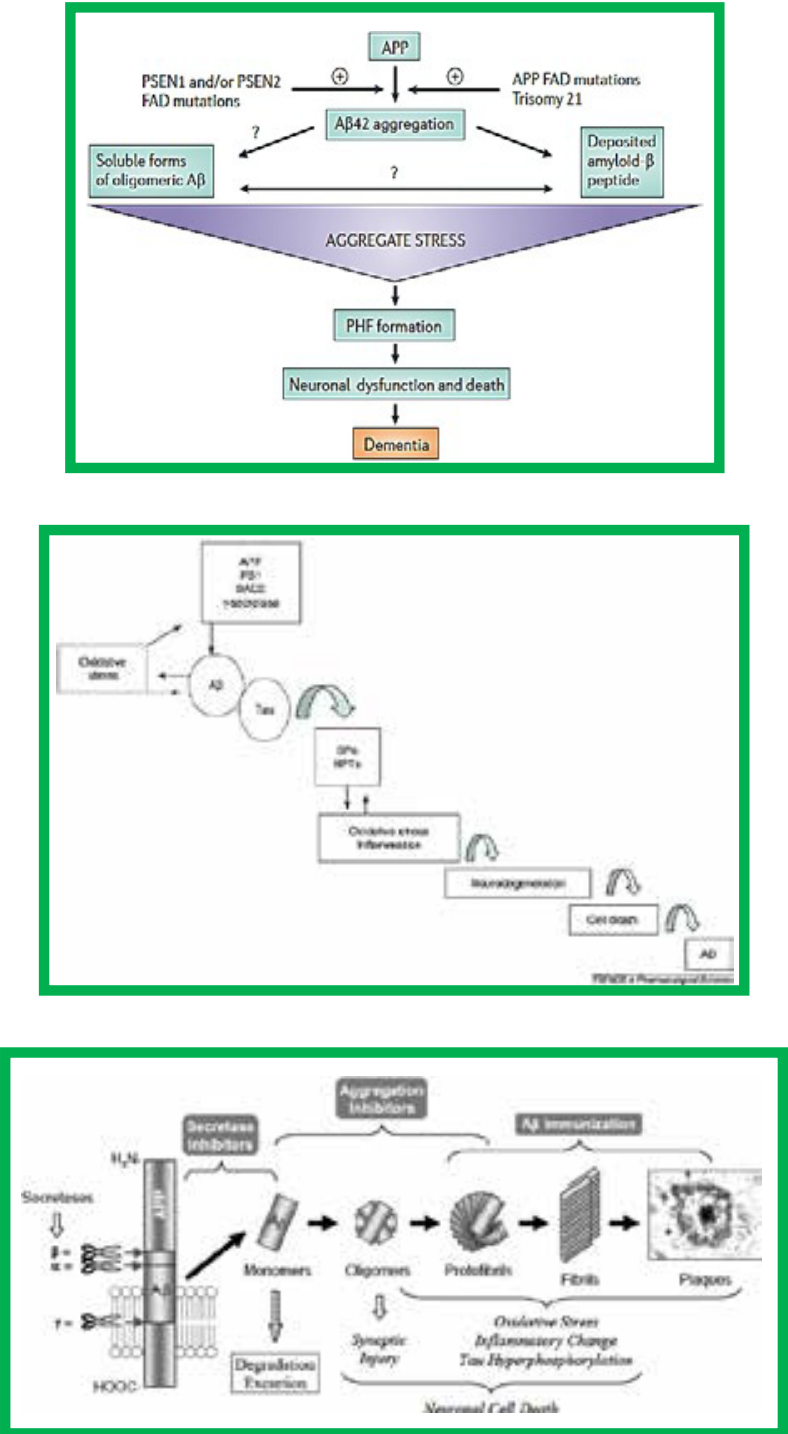

Amyloid Beta Hypothesis Oxidative stress Hypothesis Glutathione [24, 25]

Schematic illustration of the $A \beta$ amyloid cascade from APP cleavage by secretases to generate $A \beta$ monomers, to plaque formation, via oligomers, protofibrils, and fibrils. Causative factors for neuronal injury are indicated in italic letters under the $A \beta$ pathway. Anti-amyloid agents are also shown in solidwhite letters above the therapeutic targets in the $A \beta$ pathway [9].

The oxidative (inflammatory) step Is the Earliest Event in Alzheimer Disease [26,27]. Observations indicate that increased oxidative damage is an early event in $\mathrm{AD}$ that decreases with disease progression and lesion formation. These findings suggest that $\mathrm{AD}$ is associated with compensatory changes that reduce damage from reactive oxygen. The activities and expression of several antioxidant enzymes such as $\mathrm{Cu} / \mathrm{Zn}$ - and Mn-superoxide dismutase, glutathione peroxidase, glutathione reductase, and catalase have been studied in $\mathrm{AD}$ and could be in part responsible for the decrease in oxidative damage we observed. 
"Clinical criteria for the diagnosis of AD include dementia established by clinical examination and neuropsychological testing, deficits in two or more areas of cognition, progressive worsening of memory and other cognitive functions, no disturbance in consciousness, onset between ages 40 and 90 , and absence of systemic disorders or other brain disease to account for the progressive cognitive decline. A diagnostic laboratory test for $\mathrm{AD}$ has not been found and $\mathrm{AD}$ remains a diagnosis of exclusion. A definitive diagnosis cannot be made without neuropathological confirmation.

Two neuropathological criteria are available for the diagnosis of AD. The major microscopic alterations in AD are SP and NFT formation, selective neuron loss and shrinkage, synapse loss, neuropil thread formation, and amyloid antipathy"[28]. Decrease in glutathione is also a major event that is associate with neurodegenerative (Alzheimer's, Parkinson's, as examples) diseases [29]. Most antioxidant defenses (SOD, GSH-PX, a-tocopherol) do not seem to be substantially changed in the aging brain, but glutathione (GSH). Concentration and the glutathione redox index are lowered [30].

\section{Looking At Glutathione in the Brain}

The event in which polypeptides are cleaved in the inner brain is the creator of a chain of other events that brings about the formation of fibrils and plaques that finally kill the neurons in the brain of the patients. This process is going on for many tears, decades. The first stages have very little expression on the behavior, memory of the sick. Under thesis circumstances.

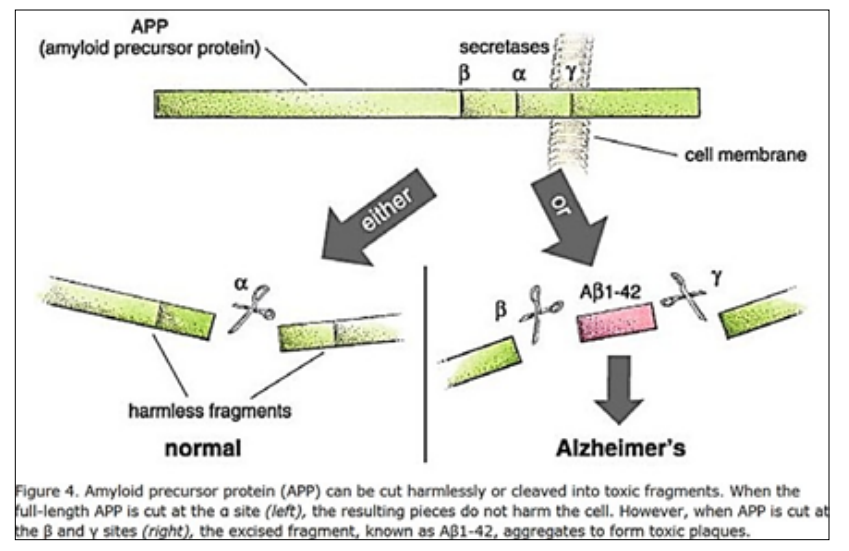

What's wrong with an Alzheimer's patient? There are about half a dozen different genetic circumstances that can trigger the disease, and probably others that are not currently known. They all lead to the same molecular pathology - the formation of aggregates of an "unfolded" fraction of a normal protein. This normal protein, the amyloid precursor protein (or APP) [a-b], is embedded in the outer membrane of cells in a variety of tissues. During its normal function, the APP is cut into segments, or peptides, at three specific sites targeted by $\alpha-, \beta$-, and $\gamma$-secretase enzymes, respectively. During the development of Alzheimer's disease, the APP protein is cleaved at the $\beta$ and $\gamma$ sites, resulting in a fracture that folds itself into a sticky, selfaccumulating form. This peptide can have between 39 and 43 amino acids, given the different variability of the $\beta$-secretase cleavage site. Not all variants are produced in equal amounts
- what is known as $A \beta 1$ - 40 is most common - and some forms are worse than others, with the most toxic peptide being A $\beta 1-42$. This fraction includes the first 42 amino acids after the $\beta$-secretase site and easily forms insoluble lumps in the brain. These aggregates are toxic and aggressively lead to dysfunction of nearby brain cells and their resulting death and removal. Once these brain cells disappear, there is currently no way to replace them $\left[31^{\mathrm{a}-\mathrm{b}}\right]$.

Disruption of glutathione homeostasis and changes in glutathione-dependent enzyme activity are increasingly involved in the induction and progression of neurological diseases, including Alzheimer's Disease, Parkinson's and Huntington's, amyotrophic atherosclerosis, and Friedrich's ataxia [32].

Various lines of evidence suggest that the operating system in the brain (oxidative stress) is an underlying factor underlying the etiology of AD. GSH levels have been consistently proven to reflect operating system status. Furthermore, the literature reviewed so far reveals a strong correlation between pathology and counting and reduced GSH levels. These findings spurred the development of tests for GSH levels as a biological marker for $\mathrm{AD}$. A number of methodologies have been developed to evaluate GSH levels in peripheral biological samples, such as blood. Recent advances in technology have also enabled noninvasive in vivo measurement of GSH directly in different brain regions using MRS. We discuss recent findings from studies using different GSH measurement methodologies and evaluate their relative potential to serve as a reliable measure of GSH levels.

Comments on new blood test suggestions for accurate early detection of Alzheimer's can be found, samples available online [33].

We suggest measuring a "biphotonic laser scanning microscopy" (TPLSM) for direct measurement of glutathione (GSH) as a combination of its S-Bimane glutathione (GSB) in blood samples after AIB-CYS-BIMANE injection (there is an analogue to S- bimanylmercaptoacetic acid as), Followed by sleep of the animal [34]. A Decrease in GSH is indicative for Oxidative Stress (OS), In the past, the presence of an efflux system in mouse cerebral micro vessel endothelial cells was examined in vitro by using a fluorescent glutathionebimane (GS-B) conjugate $[35,36]$. Oxidative stress and the diminishing Glutathione because of this early process suggest that Glutathione can be viewed as a molecular whistleblower for the Alzheimer's Disease [37].

It was found (Post Mortem) that in certain regions of the brain, GSH reduction in these regions correlated with decline in cognitive functions [38]. Receiver operator characteristics analyses evidenced that hippocampal GSH robustly discriminates between mild cognitive impairment (MCI) and healthy controls with $87.5 \%$ sensitivity, $100 \%$ specificity, and positive and negative likelihood ratios of $8.76 / .13$, whereas cortical GSH differentiates MCI and AD with $91.7 \%$ sensitivity, 
$100 \%$ specificity, and positive and negative likelihood ratios of 9.17/.08.

\section{Conclusion}

The present study provides compelling in vivo evidence that estimation of GSH levels in specific brain regions (with magnetic resonance spectroscopy) constitutes a clinically relevant biomarker for $\mathrm{MCI}$ and $\mathrm{AD}$. Glutathione relates to neuropsychological functioning in mild cognitive impairment [39].

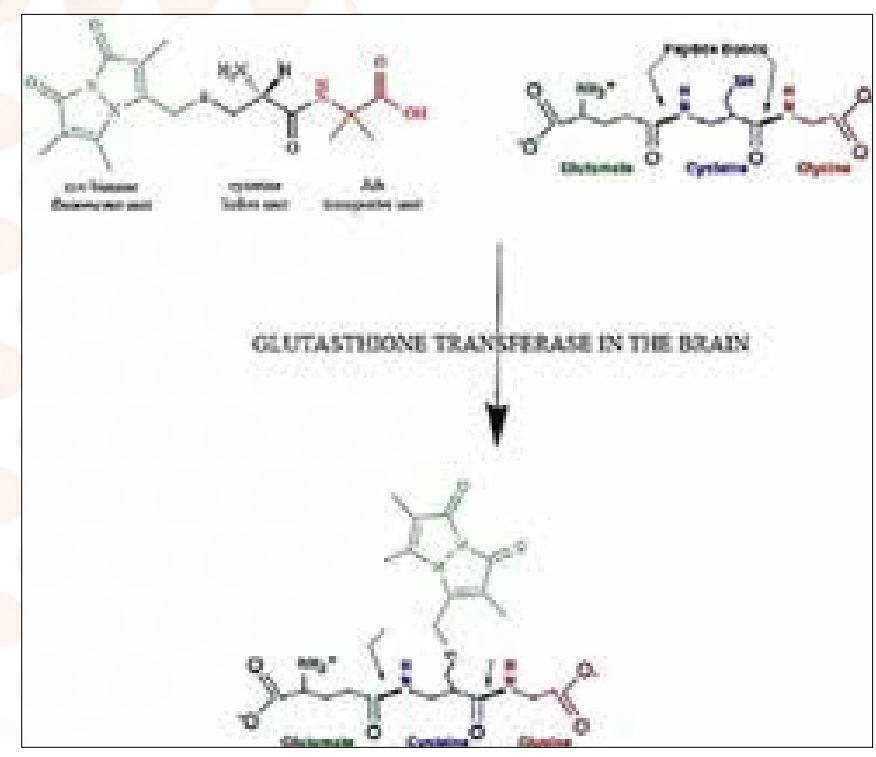

The Staining of Glutathione in the living brain and then determining the content in the blood

\section{Oxidative Stress Hypothesis -Neuropathic diseases [40]}

To defend against free radicals, living organisms have learned over time to generate antioxidants and repair enzymes to remove and/or repair molecules that are oxidized. A few enzymatic antioxidants are synthesized by cells. These include $\mathrm{Cu} / \mathrm{Zn}$ - and $\mathrm{MN}$-superoxide dismutase (SOD) methionine sulfoxide reductase [41]. Other none-enzymatic antioxidants and metal chelators. Researchers pointed out that there is a crucial role of metal ions in neurodegeneration, it masy become the basis for a promising therapeutic strategy, a chelation therapy could be a valuable therapeutic approach, since metals are a pharmacological target for the rationale design of new therapeutic agents directed towards the treatment of neurodegeneration $[42,43]$.

\section{Metall Ions}

Metal ion chelators have been suggested as potential therapies for diseases involving metal Ion imbalance. Neurodegeneration is an excellent target for exploiting the metal chelator approach to therapeutics. In contrast to the direct chelation approach in metal ion overload disorders, in neurodegeneration the goal seems to be a better and subtle modulation of metal ion homeostasis, aimed at restoring ionic balance. Thus, moderate chelators able to coordinate deleterious metals without disturbing metal homeostasis are needed. To date, several chelating agents have been investigated for their potential to treat neurodegeneration, and a series of 8-hydroxyquinoline analogues showed the greatest potential for the treatment of neurodegenerative diseases.

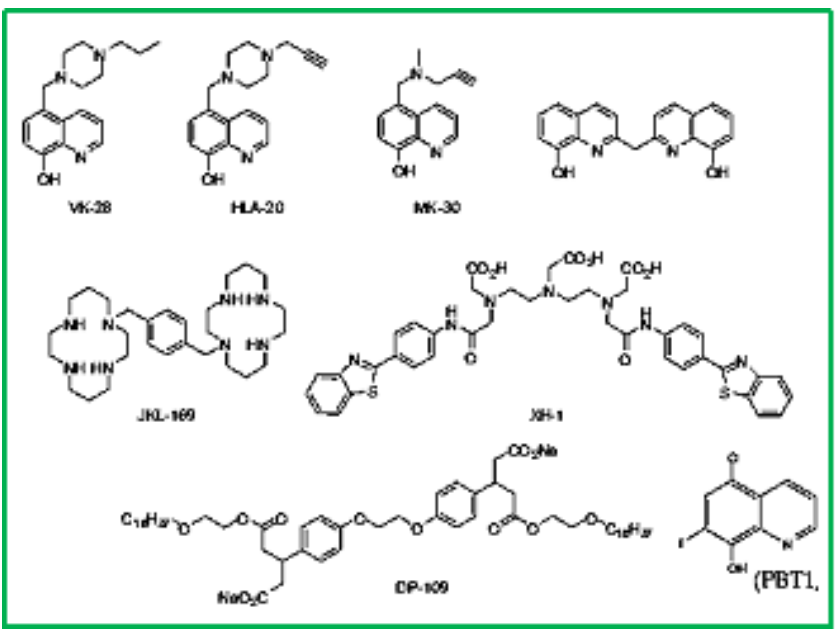

Chemical structure of chelators tested in AD

A series of 8-hydroxyquinoline analogues (VK-28, HLA20 and MA-30) have shown the greatest potential for the treatment of several neurodegenerative diseases and one of these compounds, clioquinol (PBT1), reached the pilot phase II clinical trial, which suggests that clioquinol improves cognition and lowers plasma levels of Ab42 in some patients.

The regional distributions of iron, copper, zinc, magnesium, and calcium in parkinsonian brains were compared with those of matched controls. In mild Parkinson's Disease (PD), there were no significant differences in the content of total iron between the two groups, whereas there was a significant increase in total iron and iron in substantia nigra of severely affected patients. Although marked regional distributions of iron, magnesium, and calcium were present, there were no changes in magnesium, calcium, and copper in various brain areas of PD [44].

\section{Oxidative Stress-Glutathione and Glutathione transferases as Biomarker}

Alzheimer's Disease (AD) is the most generic A type of degenerative disorder with dementia. In its Spanish form, AD results from a combination of genetic factors with various Afghan events. Among them, oxidative metabolic reactions and their by-products have been consistently affected in the pathogenesis of $\mathrm{AD}$ and represent the biological basis for the "oxidative stress hypothesis" of AD. Many studies demonstrate that various biological markers of mediating events with increased oxidative stress in the AD brain. Brain glutathione levels - a new Alzheimer's disease [45].

Metal Ions, $\mathrm{pH}$, and Cholesterol Regulate the Interactions of Alzheimer's Disease Amyloid- $\beta$ (A $\beta$ ) Peptide with Membrane Lipid. The interaction of $A \beta$ peptides with the lipid matrix of neuronal cell membranes plays a key role in the pathogenesis of Alzheimer's Disease. By using EPR and CD spectroscopy, it 
was found that in the presence of $\mathrm{Cu}^{2+}$ or $\mathrm{Zn}^{2+}, \mathrm{pH}$, cholesterol, and the length of the peptide chain influenced the interaction of these peptides with lipid bilayers. In the presence of $\mathrm{Zn}^{2+}, \mathrm{A} \beta 40$ and $\mathrm{A} \beta 42$ both inserted into the bilayer over the $\mathrm{pH}$ range 5.5-7.5, as did $\mathrm{A} \beta 42$ in the presence of $\mathrm{Cu}^{2+}$. In a comprehensive research work, scientists noticed that a significantly lower glutathione content was present in pooled samples of putamen, globus pallidus, substantia nigra, nucleus basalis of Meynert, amygdaloid nucleus, and frontal cortex of PD brains with severe damage to substantia nigra, whereas no significant changes were observed in clinicopathologically mild forms of PD [36]. The quantitative imaging of glutathione in hippocampal neurons and glia in culture using mono- or chloro-bimane refers to the Kosower and collaborators work. There is Oxidative Damage Is the Earliest Event in Alzheimer Disease [46,47]. Gutathione S-transferase, commonly abbreviated as GST, refers to a group of enzymes that employ glutathione in many reactions that contribute to the conversion of many compounds such as therapeutic drugs, carcinogens, and products involved in oxidative stress. Glutathione is an essential metabolic molecule produced in the liver of humans and animals. GST (Glutathione S-transferase) from a family of detoxifying enzymes contains a lot of micro-cytokine and mitochondrial proteins, which make up considerable parts of the enzyme's body. They exist in prokaryotes and macriotics, where they play the role of speeding up different responses and at the same time receive xenobiotic and endogenous substrates. Each of the eukaryotic species has multiple GST isoenzymes that are bound to cytosols and membranes. Each exhibits catalytic and non-catalytic binding properties.

The is decreased glutathione transferase activity in brain and ventricular fluid in Alzheimer's Disease [48]. Thiols in general, which are components of many proteins and simple molecules, such as glutathione (GSH) and cysteine (Cys), play an important role in the cellular antioxidant defense system. $1 \mathrm{GSH}$ is the most abundant intracellular nonprotein thiol (1-10 mM). 2 It has a pivotal role in maintaining the reducing environment in cells and acts as the redox regulator because thiols exist in redox equilibrium between sulfhydryl and disulfide forms.3-5 Intracellular thiol levels change dramatically in the response to oxidative stress. 1 Thus, the quantitative detection of intracellular thiols is of great importance for investigating cell functions. Blood-Brain Barrier-Penetrating 6-Halogenopurines Suitable as Pro-Probes for Positron Emission Tomography are Substrates for Human Glutathione Transferases [49]. Scientist developed a spectrophotometric assay for the glutathione conjugation and determined specific activities with a range of human GSTs as well as some rat GSTs for comparison. The ubiquitous GST P1-1 showed the highest activities with the 6- halogenopurines, which bodes well for the application of pro-probes for human investigations.

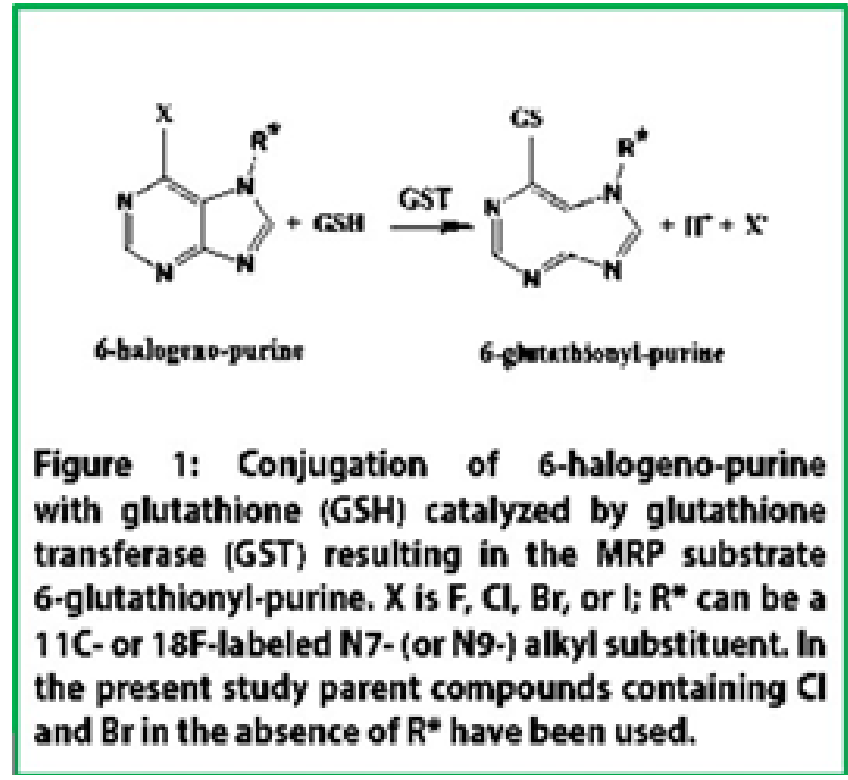

Glutathione transferase assay

Since bromo- (or chloro-) bimanes were shown to have a very useful and sensitive application in reacting with thiols to produce fluorescent labelling, attempts were made to stain brain tissues [50]. Glands and galea with the direct use of the halo-bimanes [51]. The enzymes of the Glutathione S-Transferases family may become instrumental in choosing glutathione Transferases level as a biomarker for Alzheimer's Disease [32,52].

Slicing brain in the laboratory serves research abundantly. However. Dealing with living brains is the way to go. In

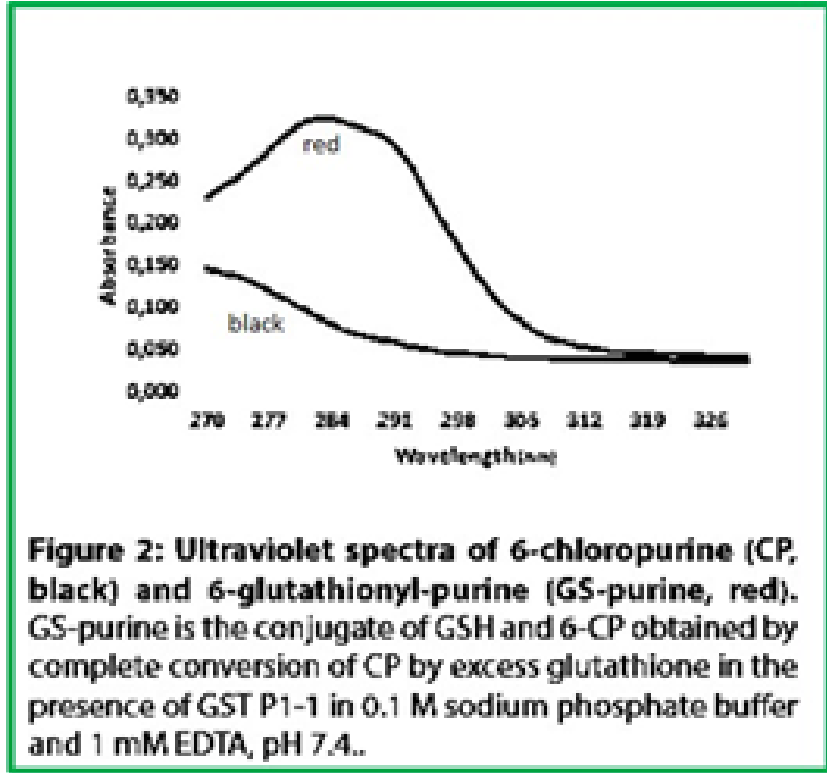

respect to the biogenesis of brain compounds, Nedergaard and coworkers found out in mice that while seeping, the waste is excreted from the brain via the spinal fluids and then transported in the blood system to the regular way the living organism gets rid of such wastes [53,54]. Scientist observe the decrease of free $\mathrm{SH}$ groups inproteins extracted from the hippocampus of $\mathrm{AD}$ patients provides additional evidence for increased oxidative damage of proteins in a vulnerable region of the AD brain [55]. 
Staining Amyloid-beta

In contrast, Use of Thioflavin derivative resolve individual A $\beta$ plaques and cerebrovascular amyloid in living microscopy. Future studies will include imaging amyloid load in transgenic mice using newly developed high-resolution micro PET, a technology that will provide a direct transition to PET imaging studies in human subjects [56,57].

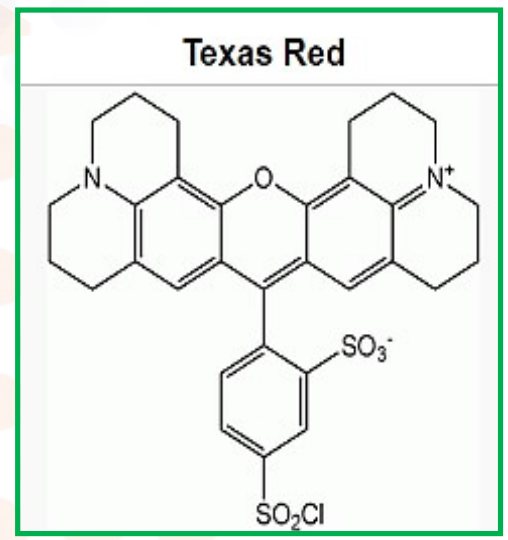

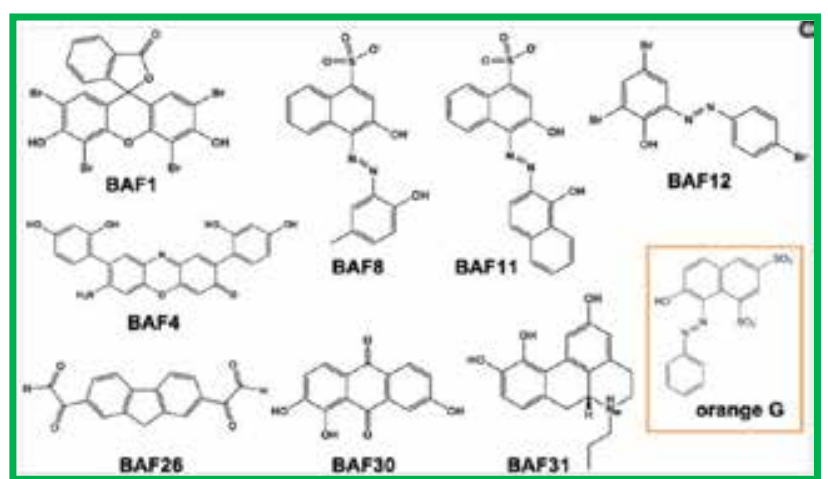

Diversified chemical structures of 8 active BAF compounds that reduce $A \beta$ toxicity.

Orange $\mathrm{G}$ in an orange box is also displayed for comparison.

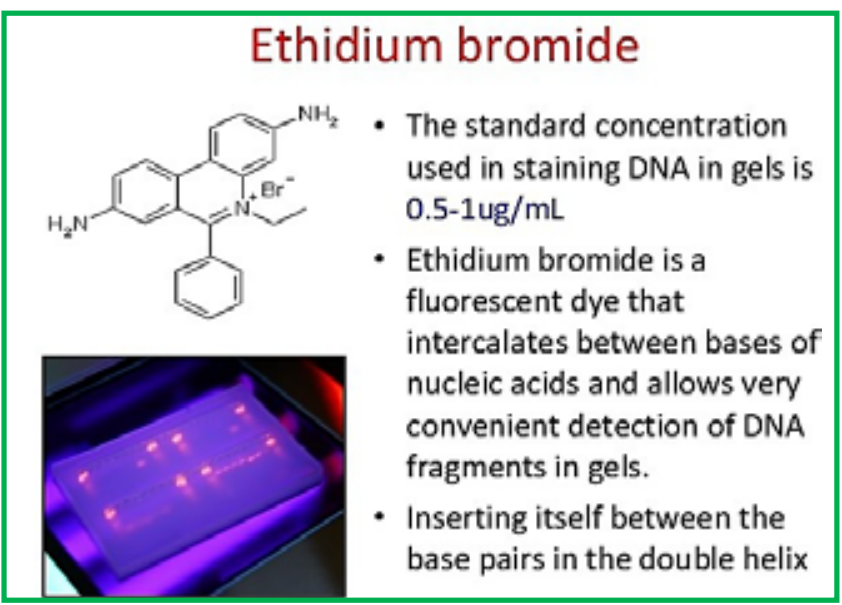

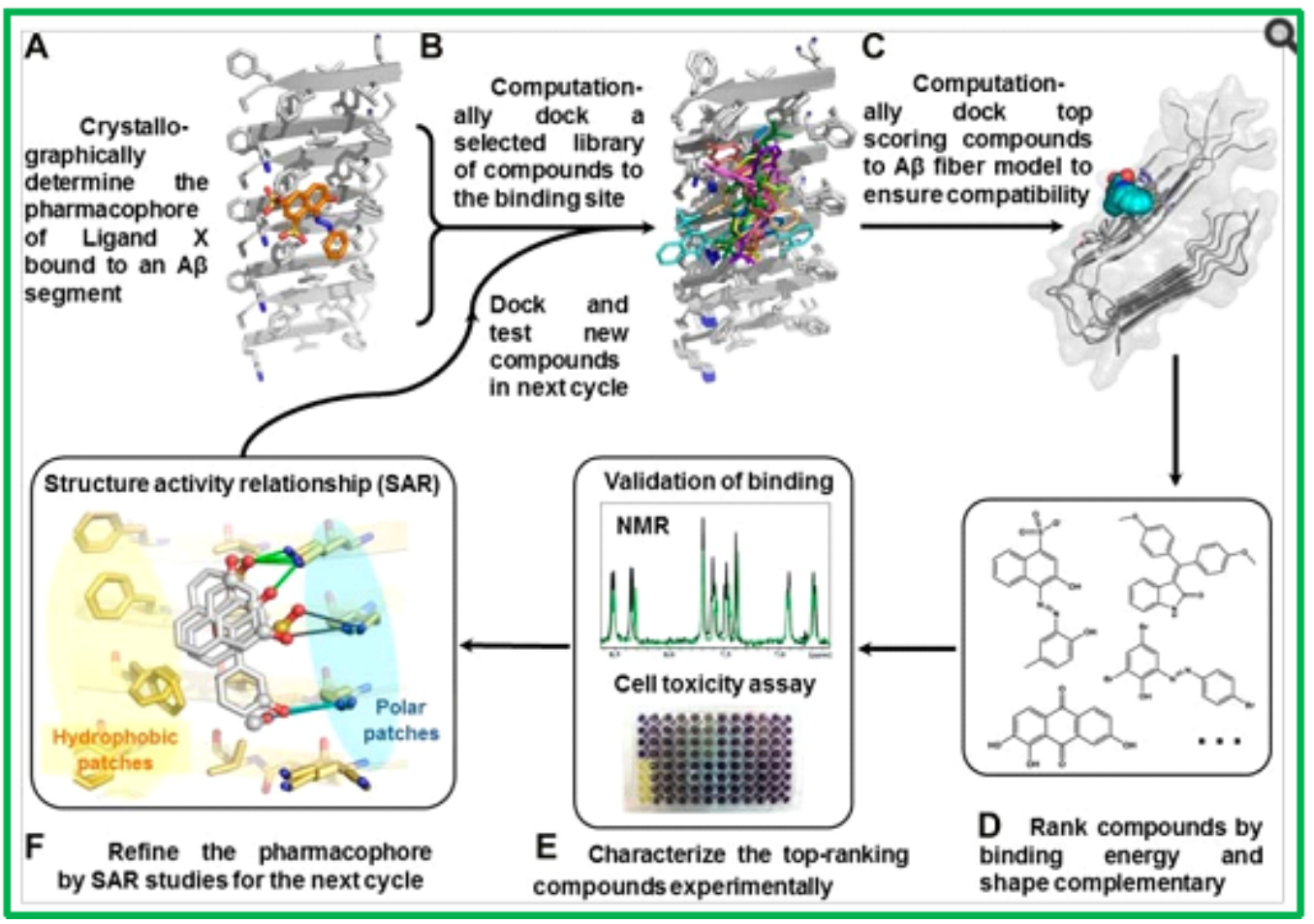

Structure-based identification of small compound inhibitors of A $\beta$ toxicity [52]. 
A typical commercial reagent for amyloid staining is "AmyloGlo" [58-61]:

Compound [53]: "Amylo-glo"; specification: Styrylbenzene derivative; Appearance: Yellow solution; Molecular Weight: 392; Filter system for visualizing: UV Ethibium Bromide: EtBr, 2,7-Diamino-10-ethyl-6-phenylphenanthridinium bromide; Appearance: light red-orange solution; Molecular Weight: 394.32. 392; Filter system for visualizing: UV Purity: Thin layer chromatography using alumina plates and a solvent system of ethanol and water (3:1) revealed the presence of two fluorescent isomers. No amount of starting material was detected. Biol. activity: Excitation Peak for Amylo-Glo: 334 Emission Peak: $533 \mathrm{~nm}$ - unbound, $438 \mathrm{~nm}$ when bound to amyloid.

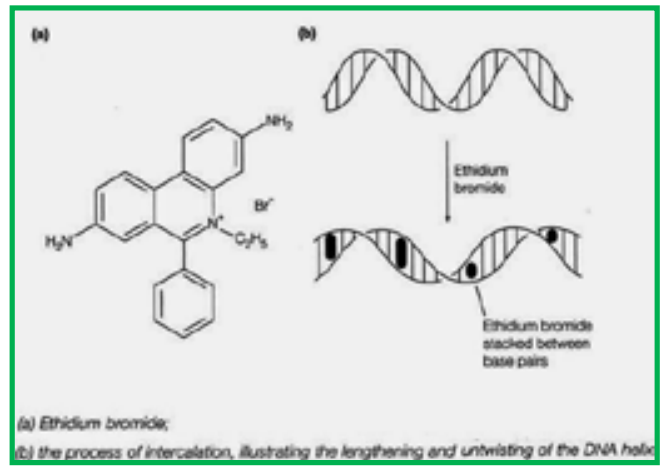

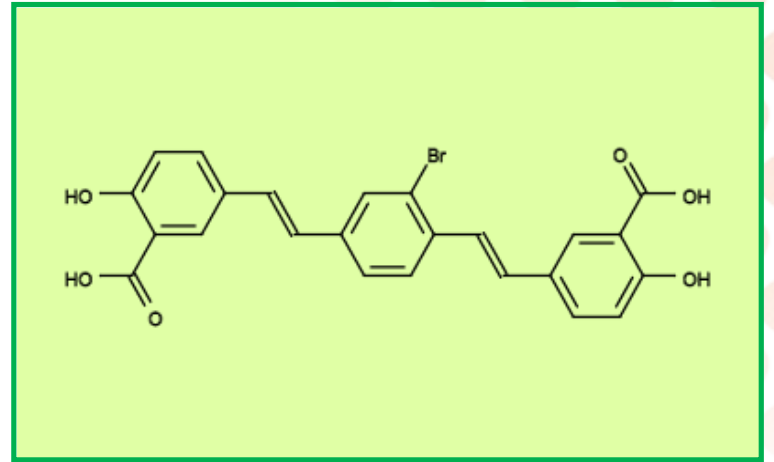

Styrylbenzene derivative and Ethidium Bromide

Today, two agents (see below) that might be useful as probes to detect their biomarkers of neurodegenerative diseases were prepared by two groups. Recently, such small molecules that could be supplied to the brain via the blood streams (abdominal or tail injection) have been reported by an Israeli and a Korean groups and introduced to the inner brain by crossing the blood brain barrier $(\mathrm{BBB})[62,63]$.

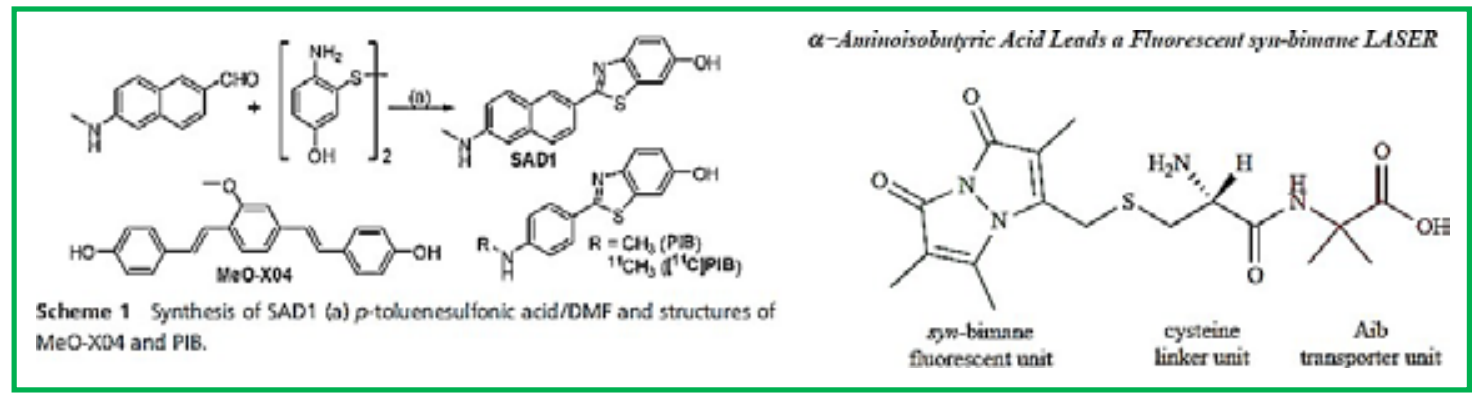

It is still a great challenge to use either biomarker, $\beta$-amyloids or Glutathione or other that are produced in the brain, probably in the hippocampus gland in the early events of the neurodegenerative Disease.

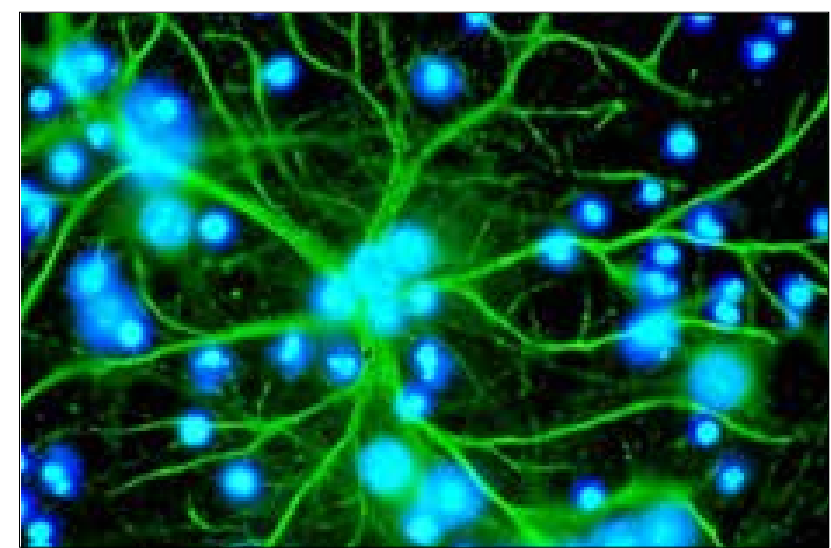

The Green Branches of An Astrocyte, one of Several Kinds of Glial Cells, Surrounded By Blue Nuclei of other Cells (Credit: Karin Pierre, Institut De Physiologie, Unil, Lausanne. Via Wikimedia Commons)[64]
Recently one may find many advertisements of blood tests for Alzheimer early diagnostics. The area is very active in this respect. Since there is no cure for Alzheimer's Disease, but medications, sensory therapy and more that can help its symptoms. And to get the full benefit of the treatments, early diagnosis is important. Learn more about Alzheimer's diagnosis and treatments. The Rowan University [65] announced that Blood test for Alzheimer's shows 100\% accuracy in early trials.

Scientist are looking for frontiers were new biomarkers foe the neurodegenerative diseases exist. Smell[66] and vision[67] are connecting directly through nerves into the brain.

\section{TAU induced diseases - High molecular weight proteins} Amyloid senile plaques and tau neurofibrillary tangles are neuropathological hallmarks Of Alzheimer's disease, 
Parkinson's disease, which accumulates in the cerebral cortex areas in people with mild cognitive impairment who are at risk for Alzheimer's disease. Non-invasive methods for detecting these abnormal proteins are potentially beneficial Development of surrogate markers for drug detection and diagnosis.

Tao protein is a protein (MAP) attached to a highly soluble micro-tube. In humans, these proteins are found primarily in neurons compared to non-neuronal cells. One of the main functions of the Tao is to change the stability of the axon micro-tubes. MAPs of the other nervous system may perform similar functions, as suggested by take-out mice that did not show abnormalities in brain development - possibly due to compensation for the lack of beta by other MAPs. [10] Tao does not exist in dendrites and is active mainly in the distal parts of the axons where it provides micro-tubular stabilization but also flexibility as needed. This is in contrast to MAP6 (STOP) proteins in the proximal parts of the axons, which essentially lock the microtubules and MAP2 which stabilizes the microtubules in dendrites.

PET of amyloid brain and tau has been shown to have a mild cognitive impairment (FDDNP-PET scan) can differentiate between people with mild cognitive impairment.

For people with Alzheimer's disease and those without cognitive impairment. 18F-PET based on the application of 2- (1- $\{6-$ [(2- [fluorine-18] fluoro-ethyl) (methyl) amino] -2-naphthyl $\}$ ethylene) melonionitrile (FDDNP) is the emission tomography of First positron (PET) molecular [68,69].

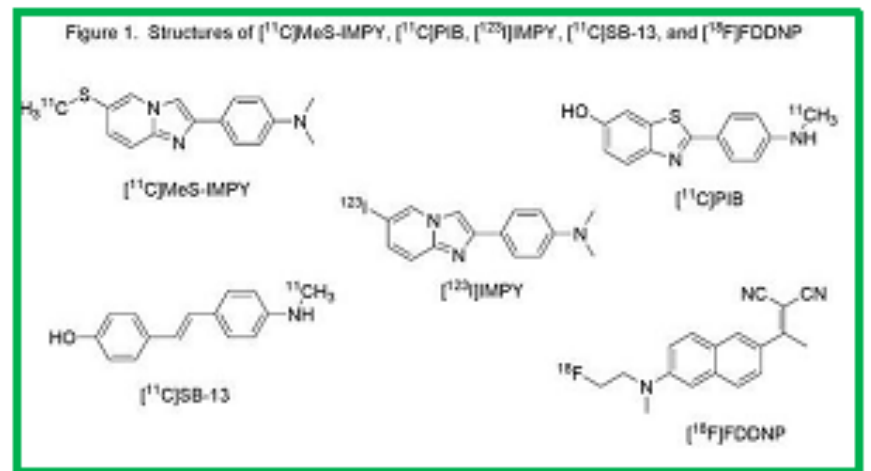

Reagents applied in PET in brain Disorder analysis imaging probe to visualize Alzheimer's Disease (AD) pathology in living humans. This technique is potentially useful as a noninvasive method to determine regional cerebral patterns of amyloid plaques and tau neurofibrillary tangles.

PET of Brain Amyloid and Tau in Mild Cognitive Impairment are indicative [70]. Are TAU-based Therapies for Alzheimer's Disease: Wave of the Future? [71].

\section{Focus Points [72]}

Tao protein is essential for proper synaptic and nerve function.

- Tao dysfunction has been replaced by the pathogenesis of Alzheimer's disease.

- Tao-based therapies for Alzheimer's disease are currently being tested. A combination of Tao-based therapies with amyloid-based therapies may be necessary to effectively treat Alzheimer's disease. APOE (genetics, apolipoprotein E) predicts the P but not the pathology of Tao Alzheimer in normal cognitive aging.

Typically, parallel PET analysis was performed with $11 \mathrm{C}$ and $18 \mathrm{~F}$ positron sources, $11 \mathrm{C}-\mathrm{PIB}$ and $18 \mathrm{~F}-\mathrm{FDlutemetamol}$ were tested. The absorption of $18 \mathrm{~F}$-flutemetamol can be easily quantified using an uptake ratio of the reference area after 80 min and provides good discrimination between $\mathrm{AD}$ patients and cancer and health. Results of these 1 steps justify further pursuit of $18 \mathrm{~F}$-flutemetamol as a biomarker for count-related amyloidosis, with wider availability for clinical and research purposes than the "parent molecule", 11C-PiB
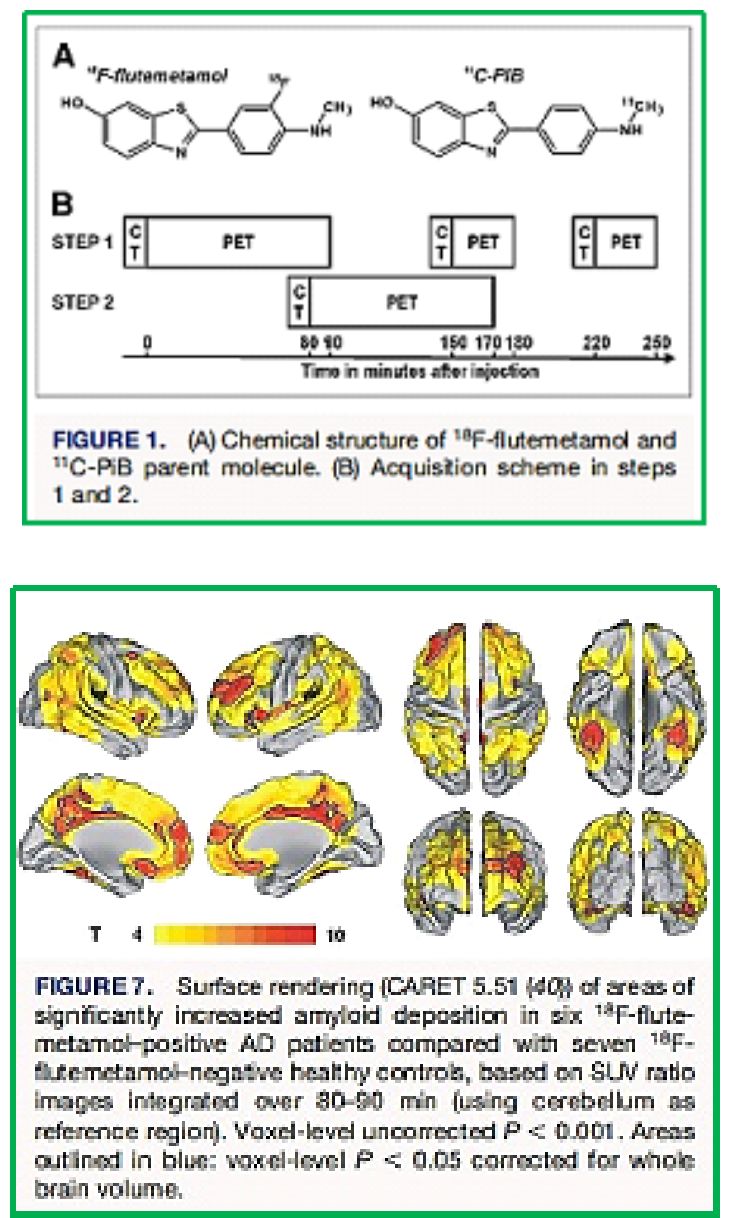

The testing of two positron sources for testing amyloids in a living $\mathrm{AD}$ patient reagent and results [52].

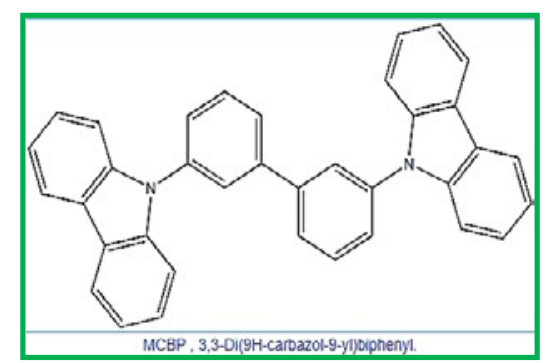



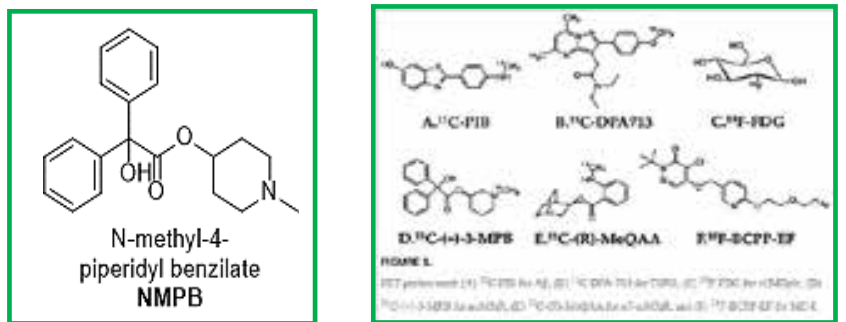

Chemicals structures of agents applied in PET analyses

Frequency of people with binding potential of the High Mean Cortex (MCBP)

For PIB, age ranged from $0 \%$ aged $45-49$ years to $30.3 \%$ aged $80-88$ years. Decreased levels of CSF A $\beta 42$ appear to start earlier (18.2\% aged 45-49 years) and increase with age at higher frequencies (50\% aged $80-88$ years) compared to the increase in MCBP. There is an effect of gene dose for the APOE4 genotype, with larger MCBP increases and larger decreases in CSF A 342 with an increased number of APOE4 alleles. People with APOE2 have no increase in MCBP with age and having higher CSP A $\beta 42$ levels than people without the APOE2 allele. No APOE4 or APOE2 effect on CSF tau or ptau181.

Mild cognitive impairment is a transitional stage between normal aging and Alzheimer's disease. A recently published study shows that the prevalence of mild cognitive impairment, characterized by a cognitive decline without impairing the ability to perform activities of daily living, is $19 \%$ among people under 75 and $29 \%$ among those 85 years. Or older. PET of amyloid and tau brain with mild cognitive impairment is recommended.

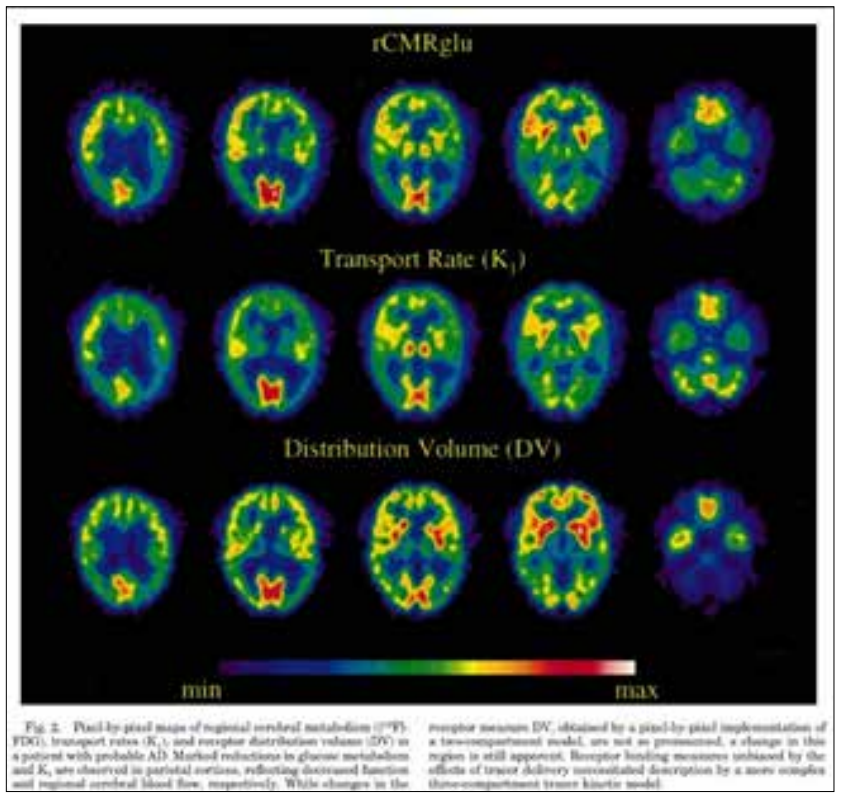

A typical result in the Alzheimer brain research: Assessment of Muscarinic Receptor Concentrations in Aging and Alzheimer Disease With [11C] NMPB and PET [73].
EXPLORING SENSES (NOSE AND EYE) AS MARKERS FOR NEUROPATHY (Disease or dysfunction of one or more peripheral nerves, typically causing numbness or weakness.)

\section{Abbreviations}

$\begin{array}{ll}\text { EPC } & : \text { Endothelial Progenitor Cells } \\ \text { DWI } & : \text { diffusion-weighted imaging } \\ \text { FLAIR } & : \text { fluid attenuated inversion recovery } \\ \text { ICAM } & : \text { intercellular adhesion molecule } \\ \text { VCAM } & : \text { vascular adhesion molecule } \\ \text { TNF } & : \text { tumor necrosis factor } \\ \text { MMP } & : \text { matrix metalloproteinase } \\ \text { TIMP } & : \text { tissue inhibitor of matrix metalloproteinase } \\ \text { ET } & : \text { endothelin } \\ \text { IL } & : \text { interleukin } \\ \text { NIHSS } & : \text { National Institutes of Health Stroke Scale } \\ \text { WBC } & : \text { white blood cells } \\ \text { RBC } & : \text { red blood cells } \\ \text { Hb } & : \text { hemoglobin } \\ \text { Ht } & : \text { hematocrit } \\ \text { INR } & : \text { International Normalized Ratio } \\ \text { SBP } & : \text { systolic blood pressure } \\ \text { DBP } & : \text { diastolic blood pressure } \\ \text { ACE } & : \text { angiotensin convertase enzyme } \\ \text { ARB } & : \text { angiotensin receptor blockers } \\ \text { rPA } & : \text { recombinant tissue plasminogen activator } \\ \text { ETOH } & : \text { chronic alcohol consumption } \\ \text { GST } & : \text { glutathione S-transferase } \\ \text { MCB } & : \text { monochlorobimane } \\ \text { HSH } & \text { and }\end{array}$

GSH CDNB, 1-chloro-2,4-dinitrobenzene

MCI : Mild Cognitive Impairment

\section{References}

1. For a review by W. A. Banks: Banks, W.A. (2012) The Neurology of AIDS 3rd Ed. Blood-Brain Barrier, Structure and Function (pp. 189-206). Oxford University Press.http:ox fordmedicine.com/view/10.1093/ med/9780195399349.001.0001/med-9780195399349chapter-003001.

2. William M. Pardridge (2005) The Blood-Brain Barrier: Bottleneck in Brain Drug Development, NeuroRx 2 (1).

3. Levine H 3rd, Walker LC (2010) Molecular polymorphism of Abeta in Alzheimer's disease. Neurobiol Aging 31: 542-548. doi: 10.1016/j.neurobiolaging.2009.02.011.

4. Walker LC, LeVine III H (2000) "The cerebral proteopathies: Neurodegenerative disorders of protein conformation and assembly". Ann Neurol 70(4): 532-540. doi: 10.1002/ana.22615

5. Chiti F, Dobson CM (2006) "Protein misfolding, functional amyloid, and human disease". Annu. Rev. Biochem 75:333366. doi: 10.1146/ annurev.biochem.75.101304.123901

6. Prusiner SB (2001) "Shattuck lecture-Neurodegenerative diseases and prions". N Engl J Med 344: 1516-1526. DOI: 10.1056/NEJM200105173442006

7. Zou WQ, Gambetti P (2005) "From microbes to prions: the final proof of the prion hypothesis". Cell 121: 155- 
157. DOI: $10.1016 /$ j.cell.2005.04.002

8. Walker LC, LeVine H, Mattson MP, Jucker M (2006) "Inducible proteopathies". TINS 29: 438-443. DOI: 10.1016/j.tins.2006.06.010

9. Meyer-Luehmann M, et al. (2006) "Exogenous induction of cerebral $\beta$-amyloidogenesis is governed by agent and host". Science 313: 1781-1784. DOI: 10.1126/ science. 1131864

10. Lewy F. H. (1912) Paralysis agitans. 1. Pathologische Anatomie. In: Handbuch der Neurologie, Band 3 (M. Lewandowsky,Hrsg.). Berlin 920-933. https:/www.dzne. de/en/science-society/public-events/lewy-symposium. html

11. In "Sample records for clinical chemistry markers", https://www.science.gov/topicpages/c/ clinical+chemistry+markers

12.

a) Eric Karran, Marc Mercken and Bart De Strooper," (2011) The amyloid cascade hypothesis for Alzheimer's disease: an appraisal for the development of therapeutics": 698 | SEPTEMBER 2011 | VOLUME 10 www.nature.com/ reviews/drugdisc

b) JohnHardy and Dennis J. Selkoe," (2002) The Amyloid Hypothesis of Alzheimer's Disease: Progress and Problems on the Road to Therapeutics"; Science 297, 353 (2002); DOI: 10.1126/science.1072994.

c) D.M. Walsh, A.M. Minogue, C. Sala Frigerio, J.V. Fadeeva, W. Wasco, D.J. Selkoe," (2007) The APP family of proteins: similarities and differences"; Biochemical Society Transactions 35(2): 416-420. ;DOI: 10.1042/ BST0350416.

13.

a) Domenico Pratico," Oxidative stress hypothesis inAlzheimer's disease: a reappraisal": Trends in Pharmacological Sciences Vol.29 No.12, 610

b) William R. Markesbery," (1997) OXIDATIVE STRESS HYPOTHESIS IN ALZHEIMER'S DISEASE"; Free Radical Biology \& Medicine 23(1): 134-147. doi. org/10.1016/S0891-5849(96)00629-6

c) Aparna Areti, Veera Ganesh Yerra, VGM Naidu, Ashutosh Kumar (2014) " Oxidative stress and nerve damage: Role in chemotherapy induced peripheral neuropathy" Redox Biology 2: 289-295. doi.org/10.1016/j.redox.2014.01.006

d) Joerg B. Schulz, Joerg Lindenau, Jan Seyfried and Johannes Dichgans," (2000) Glutathione, oxidative stress and neurodegeneration"; Eur. J. Biochem. 267, $4904 \pm 4911$ (2000) q FEBS 2000DOI: 10.1046/j.14321327.2000.01595.x

14. Nazzareno Ballatori, Suzanne M. Krance, Sylvia Notenboom, Shujie Shi, Kim Tieu, and Christine L. Hammond (2009) "Glutathione dysregulation and the etiology and progression of human diseases"; Biol Chem 390(3): 191-214. doi:10.1515/BC.2009.033.

15. Dale A. Dickinson, Henry Jay Forman (2002) “ Cellular glutathione and thiols metabolism"; Biochemical Pharmacology 64: 1019-1026. DOI: 10.1016/S00062952(02)01172-3

16. a) Julie Keelan, Nicola J. Allen, David Antcliffe, Shoubik Pal, and Michael R. Duchen," (2001) Quantitative Imaging of Glutathione in Hippocampal Neurons and Glia in Culture Using Monochlorobimane"; Journal of Neuroscience Research 66: 873-884. DOI: 10.1002/jnr.10085

b) Xiaojian Sun, Andy Y. Shih, Helge C. Johannssen, Heidi Erb, Ping Li, and Timothy H. Murphy," (2006) Twophoton Imaging of Glutathione Levels in Intact Brain Indicates Enhanced Redox Buffering in Developing Neurons and Cells at the Cerebrospinal Fluid and BloodBrain Interface"; THE JOURNAL OF BIOLOGICAL CHEMISTRY 281(25) 17420-17431. DOI 10.1074/jbc. M601567200.

17. AKIHIKO NUNOMURA, GEORGE PERRY, GJUMRAKCH ALIEV, KEISUKE HIRAI, ATSUSHI TAKEDA, ELIZABETH K. BALRAJ, PAUL K. JONES, HOSSEIN GHANBARI, TAKAFUMI WATAYA, SHUN SHIMOHAMA, SHIGERU CHIBA, CRAIG S. ATWOOD, ROBERT B. PETERSEN, MARK A. SMITH" (2001) Oxidative Damage Is the Earliest Event in Alzheimer Disease"; Journal of Neuropathology and Experimental Neurology 60(8): 759 767./doi.org/10.1093/ jnen/60.8.759

18.

a) Bengt Mannervik \& Birgitta Sjodin" Blood-Brain Barrier-Penetrating 6-Halogenopurines Suitable as Pro-Probes for Positron Emission Tomography are Substrates for Human Glutathione Transferases"; Pharmaceutical Bioprocessing, ISSN 2048-9145, 4(2): 25-30 p., http://www.diva-portal.org/smash/record. pid=diva2\%3A1079504\&dswid=7731\#sthash.1tcAJenV. dpbs

b) By BRIAN F. COLES and FRED F. KADLUBAR," Human Alpha Class Glutathione S-Transferases: Genetic Polymorphism, Expression, and Susceptibility to Disease"; METHODS IN ENZYMOLOGY, VOL. 401 0076- 6879/05. DOI: 10.1016/S0076-6879(05)01002-5

c) PHILIP G. BOARD and M. W. ANDERS," Human Glutathione Transferase Zeta"; METHODS IN ENZYMOLOGY 401: 0076-6879. DOI: 10.1016/S00766879(05)01004-9

19. Peter Schröder and Andreas Stampfl (1999) “Visualization of Glutathione Conjugation and Inducibility of Glutathione S- Transferases in Onion (Allium cepa L.) Epidermal Tissue"; Z. Naturforsch. 54c, 1033-1041. received August 2/September 3, 1999 page 1034. | DOI: https://doi. org/10.1515/znc-1987-9-1026

20. D.M. Walsh, A.M. Minogue, C. Sala Frigerio, J.V. Fadeeva, W. Wasco, D.J. Selkoe," (2007) The APP family of proteins: similarities and differences"; Biochemical Society TransactionsApr 01, 2007,35(2): 416-420;DOI: 10.1042/BST0350416.

21. Acosta D, Wortmann M (2009): Alzheimer's Disease International World Alzheimer Report 2009. In: Prince M, Jackson J, editors. London, United Kingdom: Alzheimer 's disease International.

22. Robert Perneczky, Panagiotis Alexopoulos, and Alexander Kurz (2014) Soluble amyloid precursor proteins and 
secretases as Alzheimer's disease biomarkers, Trends in Molecular Medicine, January 20(1): 8, http://dx.doi. org/10.1016/j.molmed.2013.10.001

23. DENNIS J. SELKOE,"(2006) Toward a Comprehensive Theory for Alzheimer's Disease Hypothesis: Alzheimer's Disease Is Caused by the Cerebral Accumulation and Cytotoxicity of Amyloid -Protein": Annals of the New York Academy of Sciences 924: 1-193. Version of Record online: 25 JAN 2006, DOI: 10.1111/j.1749-6632.2000. tb05554.x.

24. Eric Karran, Marc Mercken and Bart De Strooper," (2011) The amyloid cascade hypothesis for Alzheimer's disease: an appraisal for the development of therapeutics": 698 SEPTEMBER 2011 | VOLUME 10 www.nature.com/ reviews/drugdisc

25. Domenico Pratico," Oxidative stress hypothesis in Alzheimer's disease: a reappraisal": Trends in Pharmacological Sciences 29(12): 610.

26. Shimon E Shatzmiller (2017) "Gut Microbes Start Neurodegeneration - The Inflammation Approach". EC Pharmacology and Toxicology SI.01 (2017): 01-03. 27. https://www.ecronicon.com/ecpt/si/ECPT-01-SI-01.pdf

a) AKIHIKO NUNOMURA, MD, PHD, GEORGE PERRY, PHD, GJUMRAKCH ALIEV, MD, PHD, KEISUKE HIRAI, PHD, ATSUSHI TAKEDA, MD, PHD, ELIZABETH K. BALRAJ, MD, PAUL K. JONES, PHD, HOSSEIN GHANBARI, PHD, TAKAFUMI WATAYA, MD, SHUN SHIMOHAMA, MD, PHD, SHIGERU CHIBA, MD, PHD, CRAIG S. ATWOOD, PHD, ROBERT B. PETERSEN, PHD, AND MARK A. SMITH, PHD,"(2001) Oxidative Damage Is the Earliest Event in Alzheimer Disease": Journal of Neuropathology and Experimental Neurology 60(8): 759 -767.

b) Shozo Furumotoa, Nobuyuki Okamura, Ren Iwata, Kazuhiko Yanai, Hiroyuki Arai and Yukitsuka Kudo," (2007) Recent Advances in the Development of Amyloid Imaging Agents": Current Topics in Medicinal Chemistry 7: 1773-1789. DOI:10.2174/156802607782507402.

28. William R. Markesbery," OXIDATIVE STRESS HYPOTHESIS IN ALZHEIMER'S DISEASE": Free Radical Biology \& Medicine 23(1): 134-147.

29.

a) Olanow, C. W (1993) A radical hypothesis for neurodegeneration. Trends Neurosci 16: 439-444.

b) Dexter, D. T.; Carter, C. J.; Agid, F.; Agid, Y.; Lees, A. J.; Jenner, P.; Marsden, C. D (1986) Lipid peroxidation as a cause of nigral cell death in Parkinson's disease. Lancet 2: 639-640.

c) Dexter, D. T.; Carter, C. J.; Wells, F. R.; Javoy-Agid, F.; Agid, Y.; Lees, A.; Jenner, P.; Marsden, C. D (1989) Basal lipid peroxidation in substantia nigra is increased in Parkinson's disease. J. Neurochem 52: 381-389.

30. GIANNI BENZI and ANTONIO MORETI," AGEAND PEROXIDATIVE STRESS-RELATED MODIFICATIONS OF THE CEREBRAL ENZYMATIC ACTIVITIES LINKED TO MITOCHONDRIA AND THE GLUTATHIONE SYSTEM": Free Radical Biology
\& Medicine 19(1): 77-101.

31

a) http://www.americanscientist.org/issues/issue. aspxd $=866 \& y=0 \&$ no $=\&$ content $=$ true $\&$ page $=4 \&$ css $=$ print

b) John Hardy, Dennis J. Selkoe (2002) The Amyloid Hypothesis of Alzheimer's Disease: Progress and Problems on the Road to Therapeutics, Science 297, 353 (2002); DOI: 10.1126/science.1072994

32. William M. Johnson, Amy L. Wilson-Delfosse and John. J. Mieyal (2012) Dysregulation of Glutathione Homeostasis in Neurodegenerative Diseases, Nutrients 4: 1399-1440. doi:10.3390/nu4101399

33. Many enterprises offer a blood test for the accurate early diagnosis of $\mathrm{AD}$. An example one can read on on: http:// www.ndtv.com/health/new-blood-test-to-accuratelydetect-early-stage-alzheimers-1417349

34. Shimon Shatzmiller, Lapidot I, Zats G (2019) Glutathione (Gsh) as a Biomarker for Brain Research [1 a-b]. BAOJ Neurol 5: 67. https://bioaccent.org/neurology/ neurology67.php

35. Homma M, Suzuki H, Kusuhara H, Naito M, Tsuruo T, Sugiyama Y (1999) High-Affinity Efflux transport system for glutathione conjugates on the luminal membrane of a mouse brain capillary endothelial cell line (MBEC4). J. Pharmacol. Exp. Ther 288(1): 198-203.

36. Keelan J, Allen, NJ, Antcliffe D, Pal S, Duchen MR (2001) Quantitative imaging of glutathione in hippocampal neurons and glia in culture using monochlorobimane. J. Neurosci. Res 66: 873- 884

37

a) Susanne G. Mueller, Michael W. Weinera, Leon J. Thal, Ronald C. Petersen, Clifford R. Jack, William Jagust, John Q. Trojanowski, Arthur W. Toga, and Laurel Beckett," (2005) Ways toward an early diagnosis in Alzheimer's disease: The Alzheimer's Disease Neuroimaging Initiative (ADNI)": Alzheimers Dement 1(1): 55-66.

b) Chava B. Pocernich and D. Allan Butterfield"(2012) Elevation of Glutathione as a Therapeutic Strategy in Alzheimer Disease": Biochim Biophys Acta 1822(5): 625-630. doi:10.1016/j.bbadis.2011.10.003.

c) Thomas L. Perry, David V. Godin, Shirley Hansen (1985) Parkinson's disease: A disorder due to nigral glutathione deficiency?, Neuroscience Letters 33(3): 305-310.

d) L. Migliore I, Fontanaa R, Colognatoa F, Coppedea G, Sicilianob L, Murri (2005) Searching for the role and the most suitable biomarkers of oxidative stress in Alzheimer's disease and in other neurodegenerative diseases, Neurobiology of Aging 26: 587-595.

38. Pravat K. Mandal, Sumiti Saharan, Manjari Tripathi, and Geetanjali Murari (2015) Brain Glutathione Levels - A Novel Biomarker for Mild Cognitive Impairment and Alzheimer's Disease, Biological Psychiatry November 78: 702-710. www.sobp.org/journal, http://dx.doi. org/10.1016/j.biopsych.2015.04.005. For more literature: http://www.biologicalpsychiatryjournal.com/article/ S0006-3223(15)00312-1/references

39. Shantel L. Duff, Jim Lagopoulos, Ian B. Hickie, Keri Diamond, Manuel B. Graeber, Simon J. G. Lewis, 
Sharon L. Naismith (2014) Glutathione relates to neuropsychological functioning in mild cognitive Impairment, Alzheimer's \& Dementia 10: 67-75.

http://dx.doi.org/10.1016/j.jalz.2013.01.005.

40. P. Jenner, Hunot, Olanow et al., (2003) "Oxidative stress in Parkinson's disease," Annals of Neurology 53(3): S26 S38. DOI: 10.1002/ana.10483

41. Chang Li and Hai-Meng Zhou," (2011) The Role of Manganese Superoxide Dismutase in Inflammation Defense"; Enzyme Research Volume 2011 (2011), Article ID 387176, 6 pages. doi.org/10.4061/2011/387176

42. Alessandra Gaeta \& 1 Robert C. Hider," (2005) The crucial role of metal ions in neurodegeneration: the basis for a promising therapeutic strategy"; British Journal of Pharmacology 146: 1041-1059. DOI: 10.1038/ 43 sj.bjp.0706416.

a) Elias Aizenman and Pier G. Mastroberardino," (2015) Metals and neurodegeneration"; Neurobiol Dis 81: 1-3. doi:10.1016/j.nbd.2015.08.012.

b) ANA BUDIMIR, "Metal ions (2011) Alzheimer's disease and chelation therapy"; Acta Pharm. 61: 1-14 Review DOI: $10.2478 / v 10007-011-0006-6$

44.

a) Peter Riederer, Emin Sofic, Wolf-Dieter Rausch, Bruno Schmidt, Gavin P. Reynolds, Kurt Jellinger, and TMoussa B. H. Youdim," (1989) Transition Metals, Ferritin, Glutathione, and Ascorbic Acidin Parkinsonian Brains"; Journal of Neurochenistry 52(2): 515-520. DOI: 10.1111/ j.1471-4159.1989.tb09150.x

b) Cyril C. Curtain, Fedá E. Ali, Danielle G. Smith, Ashley I. Bush, Colin L. Mastersł and Kevin J. Barnham,” (2003) Metal Ions, $\mathrm{pH}$, and Cholesterol Regulate the Interactions of Alzheimer's Disease Amyloid- $\beta$ Peptide with Membrane Lipid"; THE JOURNAL OF BIOLOGICAL CHEMISTRY 278(5): 2977-2982. DOI $10.1074 / \mathrm{jbc}$. M205455200

45. Pravat K. Mandal, Sumiti Saharan, Manjari Tripathi, and Geetanjali Murari," (2015) Brain Glutathione Levels A Novel Biomarker for Mild Cognitive Impairment and Alzheimer's Disease"; Biological Psychiatry 78(10): 702710. doi.org/10.1016/j.biopsych.2015.04.005

46.

a) Julie Keelan, Nicola J. Allen, David Antcliffe, Shoubik Pal, and Michael R. Duchen," (2001) Quantitative Imaging of Glutathione in Hippocampal Neurons and Glia in Culture Using Monochlorobimane"; Journal of Neuroscience Research 66: 873-884 (2001). DOI: 10.1002/jnr.10085.

b) Annette E. Radkowsky and Edward M. Kosower," (1989) Bimanes. 17. (Haloalky1)- 1,5-diazabicyclo [3.3.0loctadienediones (Halo-9,1O-dioxabimanes): Reactivity toward the Tripeptide Thiol, Glutathione"; J. Am. Chem. SOC 108: 4527-4531. DOI: 10.1021/ ja00275a045

c) NECHAMA S. KOSOWER, EDWARD M. KOSOWERGERALD L. NEWTON, AND HELEN M. RANNEY," (1979) Bimane fluorescent labels: Labeling of normal human red cells under physiological conditions";
Proc. Natl. Acad. Sci. Cell Biology. USA 76(7): 33823386.

d) EISUKE SATO, MARI SAKASHITA, YUICHI KANAOKA AND EDWARD M. KOSOWER,” (1988) Organic Fluorescent Reagents XIV. Novel Fluorogenic Substrates for Microdetermination of Chymotrypsin and Aminopeptidase: Bimane Fluorescence Appears after Hydrolysis “; BIOORGANIC CHEMISTRY 16: 298-306.

47. Akihiko nunomura, george perry, gjumrakch aliev, keisuke hirai, atsushi takeda, elizabeth k. Balraj, paul k. Jones, hossein ghanbari, takafumi wataya, shun shimohama, shigeru chiba, craig s. Atwood, robert b. Petersen, mark a. Smith," (2001) Oxidative Damage Is the Earliest Event in Alzheimer Disease"; Journal of Neuropathology and Experimental Neurology 60(8): 759-767. /doi. org/10.1093/jnen/60.8.759

48. M.A. Lovell, C. Xie, W.R. Markesbery (1998) Decreased glutathione transferase activity in brain and ventricular fluid in Alzheimer's disease"; Neurology 51(6): 15621566. doi: http://dx. doi.org/10.1212/WNL.51.6.1562

49. Bengt Mannervik \& Birgitta Sjodin," (2016) BloodBrain Barrier-Penetrating 6-Halogenopurines Suitable as Pro-Probes for Positron Emission Tomography are Substrates for Human Glutathione Transferases"; Pharmaceutical Bioprocessing 4(2): 25-30.http://www.divaportal.org/smash/record. pid=diva2\%3A1079504\&dswid=7731\#sthash.1tcAJenV. dpbs

50. Mate KE, Kosower NS, White IG, Rodger JC.," (1994) Fluorescent localization of thiols and disulfides in marsupial spermatozoa by bromobimane labelling" 37(3): 318-325. DOI: $10.1002 / \mathrm{mrd} .1080370311$

51. Masashi Homma, Hiroshi Suzuki, Hiroyuki Kusuhara, Mikihiko Naito, Takashi Tsuruo, Yuichi Sugiyama,"(1999) High-Affinity Efflux Transport System for Glutathione Conjugates on the Luminal Membrane of a Mouse Brain Capillary Endothelial Cell Line (MBEC4)"; The Journal Of Pharmacology And Experimental Therapeutics 288 (1): 198-203.

52. Peter Schröder and Andreas Stampfl," (1999) Visualization of Glutathione Conjugation and Inducibility of Glutathione S- Transferases in Onion (Allium cepa L.) Epidermal Tissue"; Z. Naturforsch. 54c: 1033-1041 (1999); received August 2/September 3, 1999 page 1034. | DOI: https://doi. org/10.1515/znc-1987-9-1026

53. Lulu Xi, Hongyi Kang, Qiwu Xu, Michael J. Chen, Yonghong Liao, Meenakshisundaram Thiyagarajan, John O’Donnell, Daniel J. Christensen, Charles Nicholson, Jeffrey J. Iliff, Takahiro Takano, Rashid Deane, and Maiken Nedergaard," (2013) Sleep Drives Metabolite Clearance from the Adult Brain", Science 18: 342(6156). doi:10.1126/science.1241224.

54. Michael Y. Aksenov, William R. Markesbery," (2001) Changes in thiol content and expression of glutathione redox system genes in the hippocampus and cerebellum in Alzheimer's disease"; Neuroscience Letters 302: 141145.

55. Xiaojian Sun, Andy Y. Shih, Helge C. Johannssen, Heidi 
Erb, Ping Li, and Timothy H. Murphy," (2006) Twophoton Imaging of Glutathione Levels in Intact Brain Indicates Enhanced Redox Buffering in Developing Neurons and Cells at the Cerebrospinal Fluid and BloodBrain Interface"; the journal of biological chemistry 281(25): 17420-17431. DOI 10.1074/jbc.M601567200.

56. Cherry, S. R. J. (2001) Fundamentals of Positron Emission Tomography and Applications in Preclinical Drug Development, Clin. Pharmacol 41: 482. DOI: 10.1177/00912700122010357

57. Lin Jiang, Cong Liu, David Leibly, Meytal Landau, Minglei Zhao Michael P Hughes, andDavid S Eisenberg," (2013) Structure-based discovery of fiber-binding compounds that reduce the cytotoxicity of amyloid beta"; eLife 2: e00857. doi: 10.7554/eLife.00857

58. Anylo-Glo" info: http://www.funakoshi.co.jp/data/ datasheet/BSS/TR-400-AG.pdf

59. http://www.histo-chem.com/p_amylo-glo.htm\#protocol

60. Sumit Sarkar, James Raymick, and Larry C. Schmued (2014) The Use of Recently Developed Histochemical Markers for Localizing Neurotoxicant Induced Regional Brain Pathologies, Toxins (Basel) 6(4): 1453-1470. doi: $10.3390 /$ toxins6041453.

61. Larry Schmueda, James Raymick, William Tolleson, Sumit Sarkar, Yi-Hong Zhang, Ashlee Bell-Cohn (2012) Introducing Amylo-Glo, a novel fluorescent amyloid specific histochemical tracer especially suited for multiple labeling and large scale quantification studies, Journal of Neuroscience Methods 209: 120-126. http://dx.doi. org/10.1016/j.jneumeth.2012.05.019

62. Inbal Lapidot, Danny Baranes, Albert Pinhasov, Gary Gellerman, Amnon Albeck, Flavio Grynszpan and Shimon E. Shatzmiller (2016) -Aminoisobutyric Acid Leads a Fluorescent syn-bimane LASER ProbeAcross the Bloodbrain Barrier, Medicinal Chemistry 12: 48-53.

63. Cheol Ho Heo, Kyung Ho Kim, Hyung Joong Kim, Sung Hoon Baik, Hyundong Song, Yong Soo Kim, Jeewoo Lee, Inhee Mook- jung and Hwan Myung Kim (2013) A twophoton fluorescent probe for amyloid-b plaques in living mice, Chem. Commun 49: 1303

64. Scientific American, https://blogs.scientificamerican.com/ brainwaves/know-your-neurons-what-is-the-ratio-of-gliato- neurons-in-the-brain.

65. http://newatlas.com/blood-test-alzheimers-100percent $/ 43767 /$

66. Matthias H. Tabert, Xinhua Liu, Richard L. Doty, Michael Serby, Diana Zamora BSc, Gregory H. Pelton, Karen Marder, Mark W. Albers, Yaakov Stern, D. P. Devanand “ (2005) A 10-item smell identification scale related to risk for Alzheimer's disease," Ann Neurol 58: 155-160. . DOI: 10.1002/ana.20533

67. Eyes offer new window into Alzheimer's disease | Science News for Students "Eyes offernew window intoAlzheimer's disease", https://www.sciencenewsforstudents.org/article/ eyes-offer-new-window-alzheimer-disease

68. Nunilo Cremades, Samuel I.A. Cohen, Emma Deas, Andrey Y. Abramov, Allen Y. Chen, Angel Orte, Massimo Sandal, Richard W. Clarke, Paul Dunne,1 Francesco A. Aprile,
Carlos W. Bertoncini, Nicholas W. Wood, Tuomas P.J. Knowles, Christopher M. Dobsonand David Klenerman," (2012) Direct Observation of the Interconversion of Normal and Toxic Forms of -Synuclein"; Cell 149(5): 1048-1059. doi.org/10.1016/j.cell.2012.03.037

69. Shin J, Kepe V, Barrio JR, Small GW “ (2011) The merits of FDDNP-PET imaging in Alzheimer's disease"; J Alzheimers Dis. Suppl 3: 135-145. doi: 10.3233/JAD2011-0008.

70. Gary W. Small, Vladimir Kepe, Linda M. Ercoli, Prabha Siddarth, Susan Y. Bookheimer, Karen J. Miller, Helen Lavretsky, Alison C. Burggren, Greg M. Cole, Harry V. Vinters, Paul M. Thompson, S.-C. Huang, N. Satyamurthy, Michael E. Phelps, Jorge R. Barrio,” (2006) PET of Brain Amyloid and Tau in Mild Cognitive Impairment"; N Engl J Med 355: 2652-2663. December 21, 2006DOI: 10.1056/ NEJMoa054625

71. Abhilash K. Desai, Pratap Chand, FRCP," (2009) Taubased Therapies for Alzheimer's Disease: Wave of the Future?"; Primary Psychiatry 16(7): 40-46.

72. John C. Morris, Catherine M. Roe, Chengjie Xiong, Anne M Fagan, Alison M. Goate, DPhil, David M. Holtzman, Mark A. Mintun," (2010) APOE Predicts A $\beta$ but not Tau Alzheimer's Pathology in Cognitively Normal Aging"; Ann Neurol 67(1): 122-131. doi:10.1002/ana.21843.

73. Jon-kar Zubieta, Robert A. Koeppe, Kirk A. Frey, Michael R Kilbourn, Thomas J Mangner, Norman I Foster, David E Kuhl," (2001) Assessment of Muscarinic Receptor Concentrations in Aging and AlzheimerDisease With [11C]NMPB and PET"; SYNAPSE 39: 275-287. DOI: $10.1002 / 1098-\quad 2396(20010315) 39: 4<275:: A I D-$ SYN1010>3.0.CO;2-3

Copyright: (C2020 Shimon Shatzmiller. This is an open-access article distributed under the terms of the Creative Commons Attribution License, which permits unrestricted use, distribution, and reproduction in any medium, provided the original author and source are credited. 